\title{
Pacemaker Neurons within Newborn Spinal Pain Circuits
}

\author{
Jie Li and Mark L. Baccei \\ Pain Research Center, Department of Anesthesiology, University of Cincinnati Medical Center, Cincinnati, Ohio 45267
}

\begin{abstract}
Spontaneous activity driven by "pacemaker" neurons, defined by their intrinsic ability to generate rhythmic burst firing, contributes to the development of sensory circuits in many regions of the immature CNS. However, it is unknown whether pacemaker-like neurons are present within central pain pathways in the neonate. Here, we provide evidence that a subpopulation of glutamatergic interneurons within lamina I of the rat spinal cord exhibits oscillatory burst firing during early life, which occurs independently of fast synaptic transmission. Pacemaker neurons were distinguished by a higher ratio of persistent, voltage-gated $\mathrm{Na}^{+}$conductance to leak membrane conductance $\left(g_{\mathrm{Na}, \mathrm{P}} / g_{\text {leak }}\right)$ compared with adjacent, nonbursting lamina I neurons. The activation of high-threshold (N-type and L-type) voltage-gated $\mathrm{Ca}^{2+}$ channels also facilitated rhythmic burst firing by triggering intracellular $\mathrm{Ca}^{2+}$ signaling. Bursting neurons received direct projections from high-threshold sensory afferents but transmitted nociceptive signals with poor fidelity while in the bursting mode. The observation that pacemaker neurons send axon collaterals throughout the neonatal spinal cord raises the possibility that intrinsic burst firing could provide an endogenous drive to the developing sensorimotor networks that mediate spinal pain reflexes.
\end{abstract}

\section{Introduction}

Landmark studies of the visual and auditory systems have demonstrated that the maturation of sensory pathways in the CNS is highly dependent upon neuronal activity that originates from two distinct sources during development (Katz and Shatz, 1996). Before the onset of visual or auditory stimulation, spontaneous action potential discharge within the network is essential for early circuit formation (Shatz and Stryker, 1988; Tritsch et al., 2007). At later stages of development, the structural and functional refinement of these circuits is driven by sensory experience during a well defined critical period (Wiesel and Hubel, 1963).

Nociceptive circuits within the superficial dorsal horn (SDH) of the spinal cord are also known to undergo a significant, activity-dependent reorganization during the neonatal period (Fitzgerald and Jennings, 1999; Beggs et al., 2002). Nonetheless, pain networks appear unique from other sensory systems in that their activity-dependent maturation does not require modalityspecific (i.e., painful) sensory experience (Waldenström et al., 2003). This provides clear evolutionary advantages by avoiding the need to sustain repetitive tissue damage to promote the development of appropriate nociceptive withdrawal reflexes (NWRs) and pain sensitivity, which facilitate survival. If painful stimuli are not normally present during early life, what might provide the activity needed for the postnatal tuning of central pain pathways? Recent work has shown that innocuous somatosensory input from the periphery provides a major source of this

\footnotetext{
Received Dec. 15, 2010; revised April 26, 2011; accepted May 6, 2011.

Author contributions: J.L. and M.L.B. designed research; J.L. and M.L.B. performed research; J.L. and M.L.B. analyzed data; M.L.B. wrote the paper.

This work was supported by National Institutes of Health Grant NS072202 (M.L.B.) and the University of Cincinnati Millennium Fund. We thank Dr. Jianguo Gu for technical advice and Drs. Judith Strong and Jun-Ming Zhang for helpful comments regarding the preparation of this manuscript.

Correspondence should be addressed to Dr. Mark L. Baccei, Pain Research Center, Department of Anesthesiology, University of Cincinnati Medical Center, 231 Albert Sabin Way, Cincinnati, 0 H 45267. E-mail: mark.baccei@uc.edu. DOI:10.1523/JNEUROSCI.6555-10.2011

Copyright $\odot 2011$ the authors $\quad 0270-6474 / 11 / 319010-13 \$ 15.00 / 0$
}

activity, as the normal maturation of the NWR requires intact tactile sensitivity during a critical period of early postnatal development (Waldenström et al., 2003; Granmo et al., 2008).

However, this does not exclude the possibility that neonatal pain circuits contain intrinsically active neurons that provide an additional source of excitatory drive to the developing network, even in the absence of significant primary afferent input. Indeed, endogenous "pacemaker" cells, which are characterized by intrinsic, oscillatory burst firing (Ramirez et al., 2004), have been identified in other regions of the immature CNS where they are instrumental to synchronizing network activity (Koshiya and Smith, 1999; Zheng et al., 2006; Thoby-Brisson et al., 2009) and the subsequent establishment of proper synaptic connectivity (Stellwagen and Shatz, 2002). Unfortunately, it remains unclear whether similar pacemaker-type neurons exist within developing central pain circuits such as the SDH.

Here, we identify a population of pacemaker neurons within lamina I of the rodent spinal cord that spontaneously generates intrinsic burst firing during early life. These results suggest that the neonatal SDH does not merely relay nociceptive information along the pain pathway but instead contains an endogenous driver of network activity.

\section{Materials and Methods}

All experiments adhered to animal welfare guidelines established by the University of Cincinnati Institutional Animal Care and Use Committee.

DiI injections. Male Sprague Dawley rat pups were anesthetized with a mixture of ketamine $(90 \mathrm{mg} / \mathrm{kg})$ and xylazine $(10 \mathrm{mg} / \mathrm{kg})$ on postnatal day $0(\mathrm{P} 0)$ to $\mathrm{P} 1$ and placed in a plaster body mold that was secured in a stereotaxic apparatus (World Precision Instruments) as described previously (Hoorneman, 1985). The scalp was incised and a small hole was made in the skull using a 30 gauge needle. The pup received a single injection (50-100 $\mathrm{nl})$ of FAST DiI oil $(2.5 \mathrm{mg} / \mathrm{ml}$; Invitrogen) into either the parabrachial nucleus $(\mathrm{PB})$ or the periaqueductal gray (PAG) using a Hamilton microsyringe ( $62 \mathrm{RN} ; 2.5 \mu$ l volume) equipped with a 28 gauge needle. Following a series of pilot experiments based on an atlas of the E22 (i.e., P0) rat brain by Altman and Bayer (1995), the following stereo- 
taxic coordinates were used (in mm; relative to lambda): PB: 2.7 caudal, 1.0 lateral, and 3.3 ventral; PAG: 1.9 caudal, 0.60 lateral, and 2.9 ventral. The skin was closed with Vetbond and the pups returned to the home cage for 2-3 d before the beginning of the electrophysiological experiments (see below). Following killing, the brain was harvested and immersed in $4 \%$ paraformaldehyde, and $30 \mu \mathrm{m}$ coronal sections were cut on a cryostat and examined using a light microscope to verify the accuracy of the injection site.

Preparation of spinal cord slices. Rats (P2-P23) or Gad-GFP mice [FVB $\mathrm{Tg}$ (GadGFP)4570Swn; The Jackson Laboratory; P0-P4] were deeply anesthetized with sodium pentobarbital $(30 \mathrm{mg} / \mathrm{kg})$ and perfused with ice-cold dissection solution consisting of the following (in $\mathrm{mM}$ ): 250 sucrose, $2.5 \mathrm{KCl}, 25 \mathrm{NaHCO}_{3}, 1.0 \mathrm{NaH}_{2} \mathrm{PO}_{4}, 6 \mathrm{MgCl}_{2}, 0.5 \mathrm{CaCl}_{2}$, and 25 glucose continuously bubbled with $95 \% \mathrm{O}_{2} / 5 \% \mathrm{CO}_{2}$. The lumbar spinal cord was isolated and immersed in low-melting-point agarose (3\% in above solution; Invitrogen) and parasagittal slices $(350-400 \mu \mathrm{m})$ were cut using a Vibroslice tissue slicer (HA-752; Campden Instruments). The slices were placed in a chamber filled with oxygenated dissection solution for $30 \mathrm{~min}$, and then allowed to recover in an oxygenated artificial CSF (aCSF) solution containing the following (in $\mathrm{mM}$ ): $125 \mathrm{NaCl}, 2.5 \mathrm{KCl}, 25$ $\mathrm{NaHCO}_{3}, 1.0 \mathrm{NaH}_{2} \mathrm{PO}_{4}, 1.0 \mathrm{MgCl}_{2}, 2.0 \mathrm{CaCl}_{2}$, and 25 glucose for $\geq 1 \mathrm{~h}$ at room temperature.

Patch-clamp recordings. After recovery, slices were transferred to a submersion-type recording chamber (RC-22; Warner Instruments) and mounted on the stage of an upright microscope (BX51WI; Olympus) that was equipped with fluorescence to allow for the identification of GFP-expressing and DiI-labeled neurons. Slices were then perfused at room temperature with oxygenated aCSF at a rate of $1.5-3 \mathrm{ml} / \mathrm{min}$.

Patch electrodes were constructed from thin-walled single-filamented borosilicate glass ( $1.5 \mathrm{~mm}$ outer diameter; World Precision Instruments) using a microelectrode puller (P-97; Sutter Instrument). Pipette resistances ranged from 4 to $6 \mathrm{M} \Omega$, and seal resistances were $>1 \mathrm{G} \Omega$. Patch electrodes were filled with a solution containing the following (in $\mathrm{mm}$ ): $130 \mathrm{~K}$-gluconate, $10 \mathrm{KCl}, 10 \mathrm{HEPES}, 10 \mathrm{Na}$-phosphocreatine, $4 \mathrm{MgATP}$, and $0.3 \mathrm{Na}_{2}$-GTP, pH 7.2 (305 mOsm). To obtain perforated patchclamp recordings, nystatin was added to the above solution at a concentration of $200 \mu \mathrm{g} / \mathrm{ml}$ with the inclusion of Lucifer yellow $(2 \mathrm{mg} / \mathrm{ml})$ to allow for verification that the membrane had not ruptured during the perforation. In the majority of experiments, intracellular calcium buffers were not used to avoid confounding effects on neuronal excitability (Schwindt et al., 1992). To examine the effects of $\mathrm{Ca}^{2+}$ chelation on bursting activity within lamina I, some experiments used the following intracellular solution (in mM): $15 \mathrm{~K}_{4}$-BAPTA, $70 \mathrm{~K}$-gluconate, $10 \mathrm{KCl}, 10$ HEPES, 10 Na-phosphocreatine, 4 MgATP, $0.3 \mathrm{Na}_{2}$-GTP, and 25 sucrose, pH 7.2 (305 mOsm).

Dorsal horn neurons were visualized with infrared-differential interference contrast and patch-clamp recordings were obtained using a Multiclamp 700B amplifier (Molecular Devices). Sampled cells were categorized as lamina I neurons if they resided within $40 \mu \mathrm{m}$ of the edge of the dorsal white matter (Lorenzo et al., 2008). Approximately 1 min after establishment of the whole-cell configuration, the spontaneous firing patterns of dorsal horn neurons were classified at the resting membrane potential. In some experiments, fast synaptic transmission was blocked via the bath perfusion of a mixture containing $10 \mu \mathrm{M}$ NBQX, $50 \mu \mathrm{M} A \mathrm{AP}-5$, $10 \mu \mathrm{M}$ GBZ (gabazine), and $0.5 \mu \mathrm{M}$ strychnine. Other studies involved the bath application of TTX (500 nM), riluzole (RIL) $(10 \mu \mathrm{M}), \mathrm{CdCl}_{2}(500$ $\mu \mathrm{M}), \omega$-conotoxin GVIA $(\omega$-CgTx $)(1 \mu \mathrm{M})$, nifedipine $(50 \mu \mathrm{M}),(1 S, 2 S)$ 2-(2-( $N$-[(3-benzimidazol-2-yl)propyl]- $N$-methylamino)ethyl)-6-fluoro1,2, 3,4-tetrahydro-1-isopropyl-2-naphtyl cyclopropanecarboxylate dihydrochloride (NNC 55-0396) (50 $\mu \mathrm{M})$, tetraethylammonium (TEA) (1 mM), apamin (200 nM), or flufenamic acid (FFA) $(200 \mu \mathrm{M})$. Cytochrome $c(0.1 \mathrm{mg} / \mathrm{ml})$ was also included in the bath solution when applying peptide toxins, to reduce nonspecific binding to the perfusion tubing. The effect of these drugs on burst generation was examined by comparing the mean burst frequency under baseline conditions (the 2 min period immediately before drug application) with that observed between 2.5 and $4.5 \mathrm{~min}$ after the onset of drug perfusion (which corresponds to a solution exchange of at least five times the volume of the recording chamber). To evaluate the effects of riluzole on action poten- tial (AP) properties, current steps (2.5 pA increments; $50 \mathrm{~ms}$ duration) were applied at a membrane potential of $-75 \mathrm{mV}$. Rheobase was defined as the minimum current step that evoked AP discharge. AP amplitude was measured as the difference between AP threshold and the peak amplitude, while the spike duration at $50 \%$ of the peak amplitude was used to calculate AP half-width.

To record persistent, voltage-gated $\mathrm{Na}^{+}$currents $\left(I_{\mathrm{Na}, \mathrm{P}}\right)$ and voltageinsensitive leak $\left(I_{\text {leak }}\right)$ currents in neonatal lamina I neurons, cells were voltage clamped at $-110 \mathrm{mV}$ in aCSF and slow ramp depolarizations to $-10 \mathrm{mV}$ were applied at $30 \mathrm{mV} / \mathrm{s}$, a rate that is expected to cause complete inactivation of the fast voltage-dependent $\mathrm{Na}^{+}$current (Fleidervish and Gutnick, 1996). TTX (500 nM) was then bath-applied and electronic subtraction used to isolate the TTX-sensitive component of the ramp current corresponding to $I_{\mathrm{Na}, \mathrm{P}}$ (see Fig. $\left.6 \mathrm{~A}, \mathrm{~B}\right)$. Conductance $\left(g_{\mathrm{Na}, \mathrm{P}}\right)$ was calculated as follows: $g_{\mathrm{Na}, \mathrm{P}}=I_{\mathrm{Na}, \mathrm{P}} /\left(V_{\mathrm{m}}-E_{\mathrm{Na}}\right)$, where $V_{\mathrm{m}}$ is the membrane voltage and $E_{\mathrm{Na}}$ is the calculated reversal potential for $\mathrm{Na}^{+}$under our experimental conditions $(\sim 68 \mathrm{mV})$. The normalized conductance $\left(g / g_{\max }\right)$ data were fit with a Boltzmann function: $g / g_{\max }=\left[1+\exp \left(\left[V_{\mathrm{m}}\right.\right.\right.$ $\left.\left.\left.-V_{1 / 2}\right] / k\right)\right]^{-1}$, where $V_{1 / 2}$ is the voltage for half-maximal activation and $k$ is the slope factor. The leak conductance $\left(g_{\text {leak }}\right)$ was measured by fitting the linear portion of the $I-V$ relationship (from $V_{\mathrm{m}}=-110$ to $-70 \mathrm{mV}$ ) using linear regression.

To classify the pattern of primary afferent input onto bursting lamina I neurons, EPSCs were evoked from a holding potential of $-70 \mathrm{mV}$ via electrical stimulation of the L4/L5 dorsal roots $(0-1 \mathrm{~mA}, 100 \mu \mathrm{s}$ to $5 \mathrm{~ms}$ duration) delivered via a second patch electrode that was connected to a constant-current stimulator (Master-8; A.M.P.I.). The threshold to evoke an EPSC was defined as the current intensity (at a duration of $1 \mathrm{~ms}$ ) that evoked a measurable EPSC in $\geq 50 \%$ of the trials. A-fiber-mediated EPSCs were classified as monosynaptic based on their ability to follow repetitive stimulation (five stimuli at $2 \times$ threshold delivered at $10 \mathrm{~Hz}$ ) with a constant latency and absence of failures. High-threshold EPSCs were considered monosynaptic if no failures were observed during $1 \mathrm{~Hz}$ stimulation.

Membrane voltages were adjusted for liquid junction potentials calculated using JPCalc software (P. Barry, University of New South Wales, Sydney, Australia; modified for Molecular Devices) unless otherwise specified. Currents were filtered at $4-6 \mathrm{kHz}$ through a $-3 \mathrm{~dB}$, four-pole low-pass Bessel filter, digitally sampled at $20 \mathrm{kHz}$, and stored on a personal computer (ICT) using a commercially available data acquisition system (Digidata 1440A with pClamp 10.0 software; Molecular Devices).

Biocytin staining and immunohistochemistry. To visualize the dendritic morphology of developing lamina I neurons, in some experiments biocytin (Invitrogen) was included in the intracellular solution at $0.4 \%$. After completion of the recording session, the slice was immersed in $4 \%$ paraformaldehyde for $2-4 \mathrm{~d}$ at $4^{\circ} \mathrm{C}$, rinsed in $0.1 \mathrm{M} \mathrm{PB}$ (three times for 30 min each), and incubated in avidin-Alexa 488 or avidin-rhodamine (Invitrogen) at 1:500 (in $0.1 \mathrm{M}$ PB plus $0.3 \%$ Triton X-100) for $2-6 \mathrm{~h}$ at room temperature. Following another rinse in $\mathrm{PB}$, slices were mounted on concave slides (Thermo Fisher Scientific) with Vectashield mounting medium (Vector Laboratories), coverslipped, and examined under a light microscope.

In a subset of these experiments, the neurotransmitter phenotype of the bursting neuron was then examined using a protocol similar to one described previously (Yasaka et al., 2010). Briefly, slices were embedded in gelatin overnight and parasagittally sectioned at a thickness of $50 \mu \mathrm{m}$ with a vibratome (Vibratome). Sections were immersed in $50 \%$ ethanol for 30 min to enhance antibody penetration and blocked with $10 \%$ normal goat serum for $1 \mathrm{~h}$. This was followed by incubation with a guinea pig antibody raised against VGLUT2 (1:5000 in $0.1 \mathrm{M} \mathrm{PB}$ plus $0.3 \%$ Triton $\mathrm{X}-100$; Millipore) for $3 \mathrm{~d}$ at $4^{\circ} \mathrm{C}$ and then an overnight incubation (at $4^{\circ} \mathrm{C}$ ) with a goat anti-guinea pig IgG conjugated to Alexa 488 (1:250 in 0.1 M PB plus $0.3 \%$ Triton X-100; Invitrogen). Sections were mounted in antifade medium, examined through a $40 \times$ lens using an Olympus BX61 fluorescent microscope equipped with a spinning disc confocal unit, and scanned with a $z$-separation of $0.5 \mu \mathrm{m}$. A neuron was classified as glutamatergic if six or more of its axonal boutons demonstrated immunoreactivity for VGLUT2 (Yasaka et al., 2010). Negative control experiments in which the primary antibody was omitted produced no visible signal. 
A

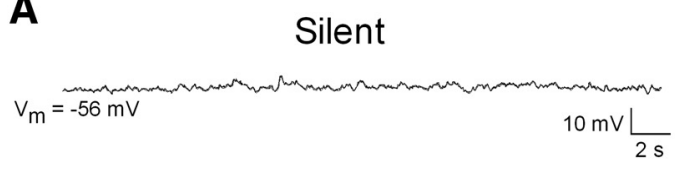

Irregular

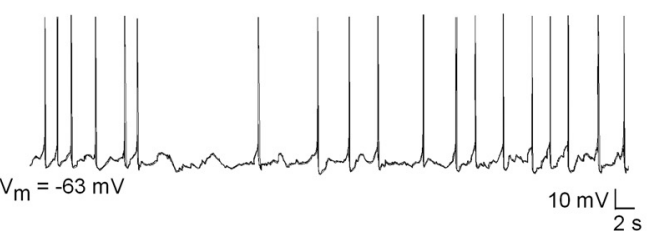

Tonic

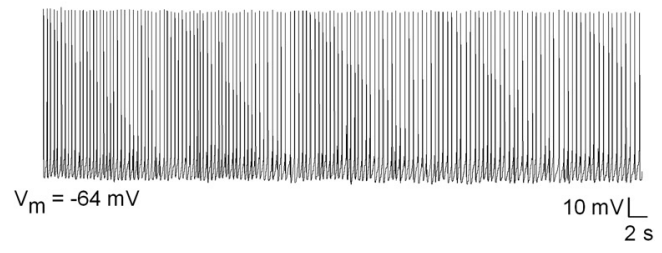

Bursting

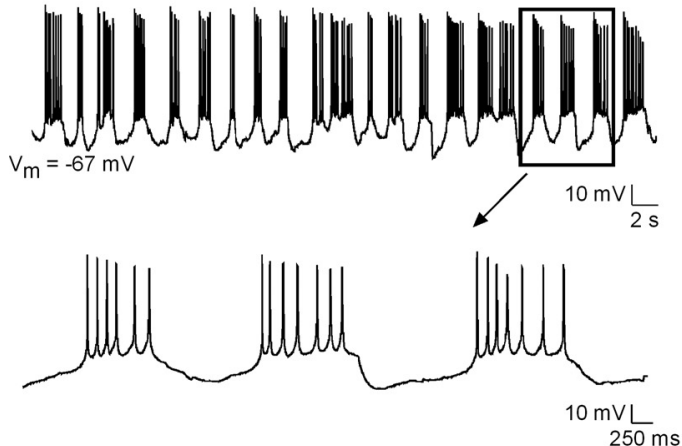

B

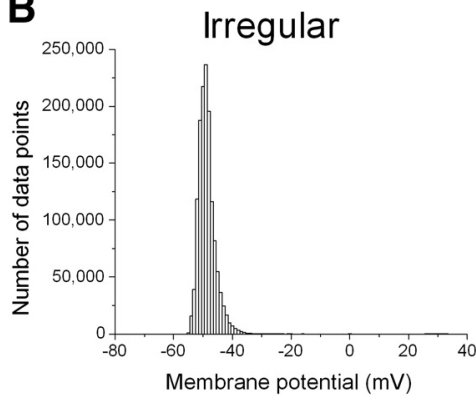

C

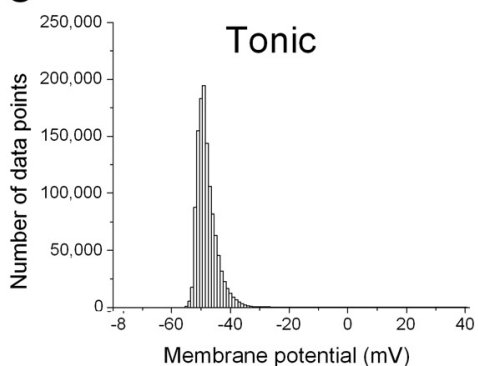

D

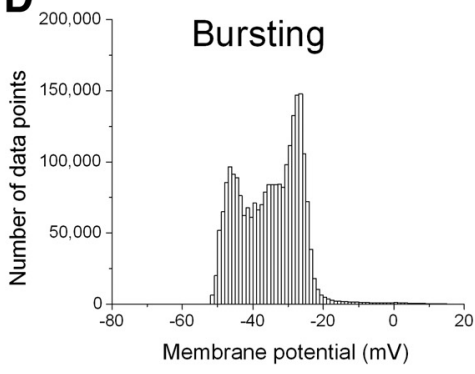

E
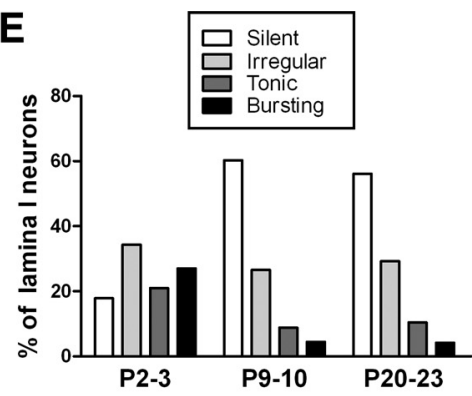

F

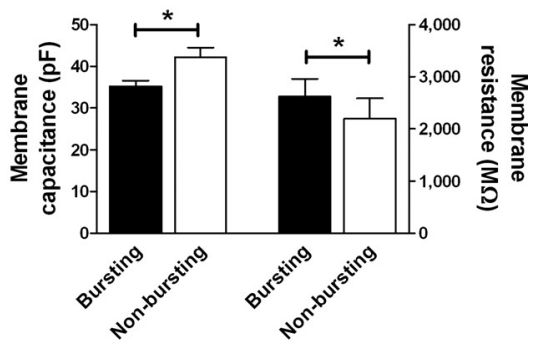

G

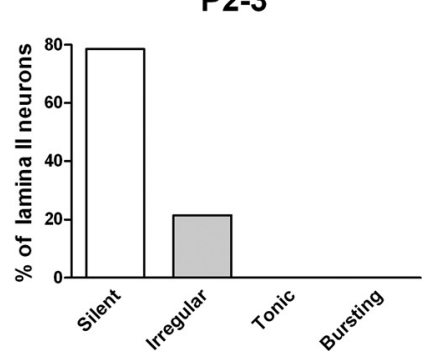

Figure 1. Spinal lamina I neurons exhibit rhythmic burst firing during early life. $\boldsymbol{A}$, Examples of the different spontaneous firing patterns observed in lamina I neurons at P2-P3. B-D, Corresponding all-points histograms showing the distribution of membrane potentials (not adjusted for liquid junction potentials) during a $90 \mathrm{~s}$ recording period (bin size, $1 \mathrm{mV}$ ). $E$, The distribution of spontaneous activity patterns in lamina I shifts significantly during postnatal development $\left(n=48-68\right.$ cells at each age; $p<0.0001, \chi^{2}$ test). $F$, Bursting lamina I neurons $(n=28)$ had a smaller membrane capacitance $\left({ }^{*} p=0.038\right.$, Mann-Whitney test) and higher membrane resistance $\left({ }^{*} p=0.014\right.$, Mann-Whitney test) compared with adjacent, nonbursting cells $(n=45)$ at $P 2-P 3$. Error bars indicate SEM. G, Both bursting and tonic neurons were absent in lamina II at P2-P3 ( $n=28 ; p<0.0001$ compared with lamina I at the same age, $\chi^{2}$ test).

Data analysis and statistics. Data were analyzed using Clampfit (Molecular Devices) and Origin (OriginLab) software. Neurons were classified as bursting if they exhibited clear plateau potentials and a distinct second peak on an all-points histogram of the membrane potential (see Fig. 1D). The distribution of spontaneous firing patterns was compared across groups using the $\chi^{2}$ test (Prism 5.0; GraphPad Software). Nonparametric tests were used in cases in which the distribution of data failed the D'Agostino and Pearson normality test (Prism) or when the number of observations was insufficient $(n<24)$ to definitively conclude that data were distributed in a Gaussian manner. As a result, the effect of various antagonists on the burst frequency was examined using Wilcoxon's signed-rank test, while the Mann-Whitney test was used to compare the passive membrane properties of bursting versus nonbursting lamina I neurons. A value of $p<0.05$ was considered significant. $n$ refers to the number of neurons sampled in a given group. Data are expressed as means \pm SEM.

\section{Results}

Rhythmic burst firing in spinal lamina I neurons during the neonatal period

To examine the prevalence and pattern of spontaneous firing in the SDH during postnatal development, we obtained in vitro whole-cell patch-clamp recordings from lamina I-II neurons in rat spinal cord slices prepared at P2-P3, P9-P10, or P20-P23. Similar age groups are commonly used to examine the maturation of nociceptive withdrawal reflexes at the behavioral level (Fitzgerald, 2005) and are thought to correspond to developmental stages before (P2-P3) and after (P9-P10 and P20-P23) the maturational state of a newborn human at full term (Adlard et al., 1973). As illustrated in Figure $1 A$, spontaneous activity (SA) within lamina I could be classified as "silent" (i.e., only subthreshold events observed), "irregular" (sporadic action potential discharge), "tonic" (continuous spiking at a constant frequency), or "bursting” (exhibiting rhythmic burst firing). At P2-P3, bursting neurons displayed slow $(\sim 1-8 \mathrm{~s}$ in duration), plateau-like potentials at a rate of $17.8 \pm 1.4$ per minute $(n=22)$, with accompanying bursts of APs superimposed at an intraburst frequency of $5.07 \pm$ $0.38 \mathrm{~Hz}$, which was significantly higher than the mean firing frequency seen in tonic cells $(3.40 \pm 0.39 \mathrm{~Hz} ; n=13 ; p=0.008$, Mann-Whitney test). The existence of a bistable membrane potential in the bursting neurons was evidenced by a distinct second peak in histograms of the membrane potential distribution (Fig. $1 B-D)$. When perforated patch-clamp recordings were obtained in a population of neonatal lamina I neurons using nystatin $(n=$ 

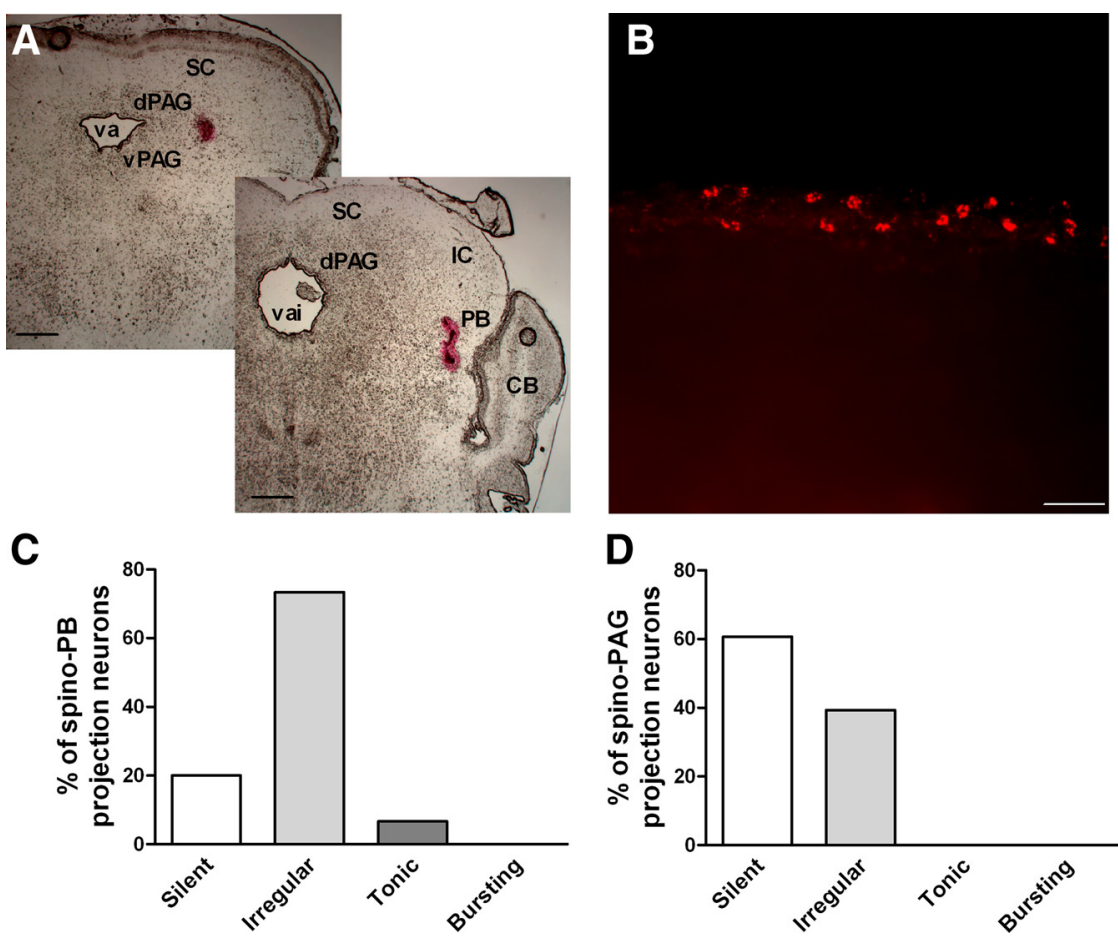

Figure 2. Spontaneous burst firing is not localized to projection neurons within the neonatal superficial dorsal horn. $\boldsymbol{A}$, Sections of neonatal rat brain illustrating Dil injection sites in the PAG (left) and the PB (right). SC, Superior colliculus; dPAG, dorsal PAG; VPAG, ventral PAG; va, aqueduct; IC, inferior colliculus; $C B$, cerebellum; vai, inferior tectal aqueduct. Scalebars, $400 \mu \mathrm{m}$. B, Frozen sagittal section $(30 \mu \mathrm{m})$ of P4 spinal cord illustrating the presence of Dil-labeled neurons within lamina lat 3 dafter injection. Scale bar, $50 \mu \mathrm{m}$. C, D, Spino-PB $(n=$ 30) projection neurons showed significantly more spontaneous activity during the neonatal period compared with spino-PAG $(n=28)$ neurons ( $p=0.003$, Fisher's exact test), but neither population exhibited rhythmic burst firing.

15), 6 cells showed evidence of burst firing with the remainder of neurons exhibiting irregular $(n=5)$, tonic $(n=2)$, and silent $(n=2)$ patterns of SA. This distribution of firing patterns was not significantly different from that seen using the whole-cell configuration at $\mathrm{P} 2-\mathrm{P} 3\left(p=0.774, \chi^{2}\right.$ test compared with data shown in Fig. $1 E$ ), demonstrating that the burst firing was not an artifact of intracellular dialysis during the whole-cell recording. As a result, given the greater technical difficulty of the nystatin recordings in spinal cord slices, whole-cell patch-clamp techniques were used in all subsequent experiments.

The distribution of these different spontaneous firing patterns changes significantly within lamina I during early postnatal development. While all subtypes of SA were found to a relatively similar extent at P2-P3, a significant increase in the fraction of cells that were silent at rest was observed by P9-P10 (Fig. 1 E), which was paralleled by a reduction in the percentage of tonic and bursting neurons at later ages $\left(p<0.0001, \chi^{2}\right.$ test). There was also a significant agedependent shift in the resting potential $\left(V_{\text {rest }}\right)$ of lamina I neurons during this period (P2-P3: $-62.3 \pm 0.8 \mathrm{mV}, n=66$; P9-P10: $-67.0 \pm 0.9 \mathrm{mV}, n=68 ; \mathrm{P} 20-\mathrm{P} 23:-67.8 \pm 1.1 \mathrm{mV}, n=48 ; p<$ 0.0001 , one-way ANOVA). To examine whether the greater prevalence of burst firing at $\mathrm{P} 2-\mathrm{P} 3$ is caused by the more depolarized $V_{\text {rest }}$ at this age, a subset of nonbursting cells from each age group was gradually depolarized (from $V_{\text {rest }}$ to approximately $-45 \mathrm{mV}$ ) by directly injecting current through the patch electrode. This depolarization recruited bursting in an additional 12\% (3 of 25) of lamina I neurons at P2-P3, 8.3\% (2 of 24) of cells at P9-P10, and only $2.1 \%$ ( 1 of 47 ) of neurons at P20-P23. This strongly suggests that the developmental reduction in the number of bursting neurons within lamina I (Fig. 1E) cannot be explained by age-related changes in $V_{\text {rest }}$. Meanwhile, bursting neurons within lamina I of the neonate were distinguished by a significantly lower membrane capacitance $\left(C_{\mathrm{m}}\right)$ and higher membrane resistance compared with adjacent, nonbursting neurons (Fig. $1 F$ ). Importantly, oscillatory burst firing within the newborn SDH was restricted to lamina I, as we failed to observe this rhythmic activity in lamina II neurons from the same spinal cord slices (Fig. 1G). These results indicate that spontaneous, rhythmic burst firing is prevalent in lamina I of the spinal cord during a brief period of early life.

\section{The population of bursting lamina I neurons includes glutamatergic interneurons}

Since spinal projection neurons comprise $\sim 5 \%$ of the overall population in lamina I and are absent from lamina II (Spike et al., 2003), the observation that burst firing selectively occurs within lamina I raises the interesting question of whether spinal projection neurons exhibit spontaneous bursting during the neonatal period. The prevalence of burst firing within lamina I at P2-P3 ( 27\%) (Fig. 1E) would argue against the notion that it was restricted to projection neurons, as would the significantly lower $C_{\mathrm{m}}$ of the bursting cells (Fig. $1 F$ ) given that projection neurons are larger than other lamina I neurons (Al Ghamdi et al., 2009). Nonetheless, this does not rule out the possibility that a subset of spontaneously bursting neurons corresponds to immature projection neurons.

To examine this question more directly, we backlabeled lamina I projection neurons by injecting Fast DiI into either the $\mathrm{PB}$ or PAG in $\mathrm{P} 0-\mathrm{P} 1$ rats (Fig. 2A,B) and recorded from these neurons at P2-P4. As expected, the membrane capacitance of the DiIlabeled neurons was significantly higher (spino-PB: $58.9 \pm 3.9$ $\mathrm{pF}, n=30$; spino-PAG: $68.2 \pm 3.4 \mathrm{pF}, n=28)$ than that of lamina I neurons that were blindly sampled (i.e., primarily corresponding to interneurons) at roughly the same age ( $40.1 \pm 1.7 \mathrm{pF} ; n=$ 68; $p<0.0001$, one-way ANOVA), which is consistent with the selective targeting of ascending projection neurons under visual guidance. The pattern of spontaneous activity varied according to the target in the brain, as a significantly greater percentage of spino-PB neurons exhibited spontaneous firing compared with the spino-PAG neurons ( $p=0.003$, Fisher's exact test). More importantly, neither spino-PB nor spino-PAG neurons exhibited rhythmic burst firing at these ages (Fig. $2 C, D$ ), suggesting that the bursting cells correspond to interneurons within lamina I of the neonate. These bursting interneurons appear morphologically heterogeneous, as visualization of their dendritic morphology via biocytin staining demonstrated that cells with fusiform $(n=11)$ (Fig. 3A), multipolar $(n=8)$ (Fig. $3 B)$, pyramidal $(n=5)$, or unclassified $(n=14)$ morphology are all capable of generating rhythmic burst firing during early life. Interestingly, the axons of the bursting neurons were not restricted to lamina I. Of the 14 bursting neurons whose axons could be visualized via biocytin staining, 10 cells sent projections to the SDH, 6 exhibited branches in the deep dorsal horn (DDH), and 5 neurons projected into the ventral horn ( $\mathrm{VH})$. The majority of bursting neurons sent axon collaterals to multiple areas of the spinal cord 
(SDH, DDH, and $\mathrm{VH}$ ), including some cells that projected to all three regions (Fig. 3C).

The functional implications of the spontaneous burst firing for the overall excitability and output of the immature SDH network will clearly depend on whether it is localized to excitatory and/or inhibitory interneurons. To examine whether bursting neurons exhibit a glutamatergic phenotype, a subset of biocytinfilled neurons were further processed for immunohistochemistry using a primary antibody raised against the vesicular glutamate transporter VGLUT2, which is commonly used as a marker for excitatory interneurons within the SDH (Maxwell et al., 2007; Yasaka et al., 2010). Of the eight bursting neurons examined, seven of these cells possessed axonal boutons that showed immunoreactivity for VGLUT2 (Fig. 3D-F).

This issue was further investigated by recording from neonatal dorsal horn neurons from transgenic mice expressing eGFP selectively in GABAergic neurons via the Gad1 promoter (Oliva et al., 2000) (Fig. $3 G$ ). Unlike the rat (Lorenzo et al., 2008), the thickness of lamina I at various stages of postnatal development has yet to be quantified in the mouse. As a result, the sampled neurons (residing within $40 \mu \mathrm{m}$ of the edge of the dorsal white matter) may include both lamina I and II neurons in the mouse, and have thus been conservatively classified as SDH neurons in the present study. Since eGFP labels a high percentage $(\sim 80 \%)$ of GABAergic neurons in the SDH at early ages (Dougherty et al., 2009) and glycinergic cells likely represent a subset of this GABAergic population (Todd and Sullivan, 1990), the vast majority (80-90\%) of adjacent, non-GFP cells are predicted to be glutamatergic neurons (Shiokawa et al., 2010). The overall prevalence of the spontaneous burst firing was lower in the neonatal mouse SDH (Fig. $3 H$ ) compared with lamina I of the rat (Fig. $1 E$ ), and it remains unclear whether this reflects genuine interspecies differences or the possibility that the greater sampling of lamina II neurons in the mouse yielded a lower overall percentage of bursting neurons. More importantly, the rhythmic burst firing was restricted to neonatal mouse SDH neurons lacking GFP expression (Fig. $3 H$ ).

Collectively, the above evidence suggests that a subset of glutamatergic interneurons within lamina I are capable of generating oscillatory burst firing during the neonatal period.

Burst firing reflects intrinsic, voltage-dependent properties of newborn lamina I neurons

To determine whether these rhythmically bursting cells represented pacemaker neurons, we next investigated whether the spontaneous burst firing was intrinsic to neonatal lamina I cells or an emergent property of the developing SDH synaptic network. As mentioned previously, in a small percentage of neurons that were silent at their resting membrane potential, bursting could be evoked by slightly depolarizing the cell with current
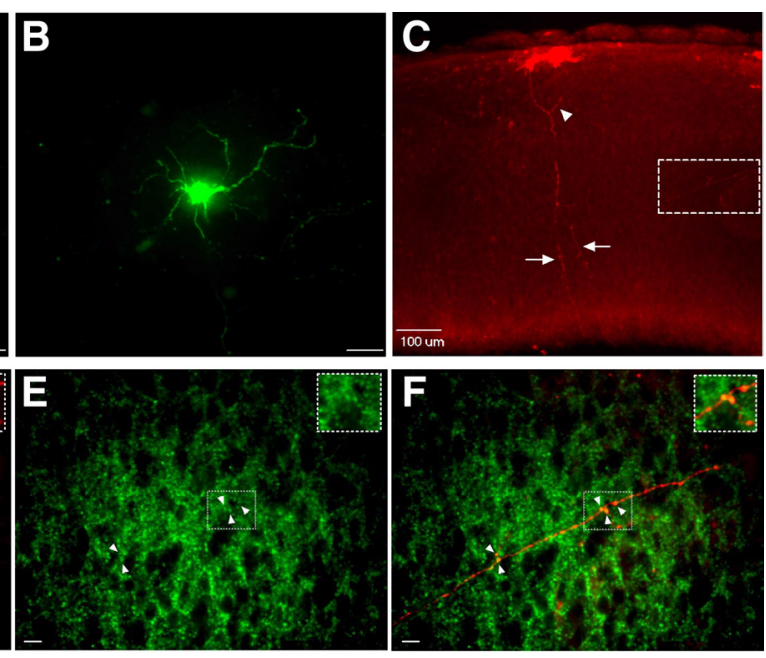

Figure 3. Glutamatergic lamina I interneurons of diverse morphology are capable of generating rhythmic bursting. $\boldsymbol{A}, \boldsymbol{B}$ ( ) inced region) (see $\boldsymbol{D}-\boldsymbol{F}$ ), and the ventral horn (arrows). $\boldsymbol{D}$, Section (of same spinal cord as shown in non-GFP (presumed glutamatergic) neurons in the newborn mouse SDH $(n=56)$, it was absent in the GABAergic population in the
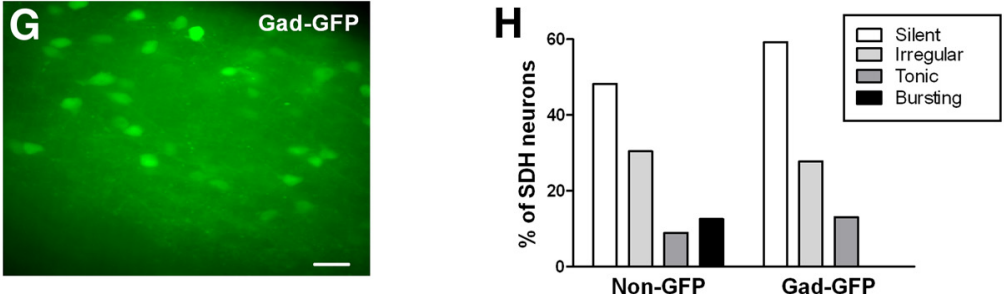

$\mathbf{H}$

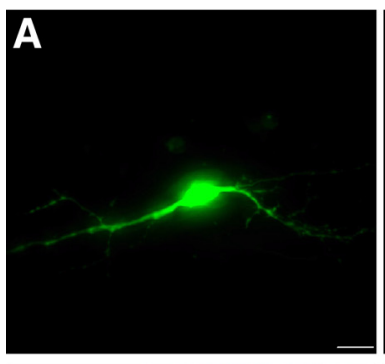

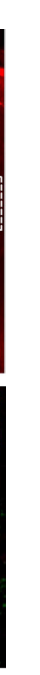

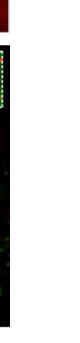




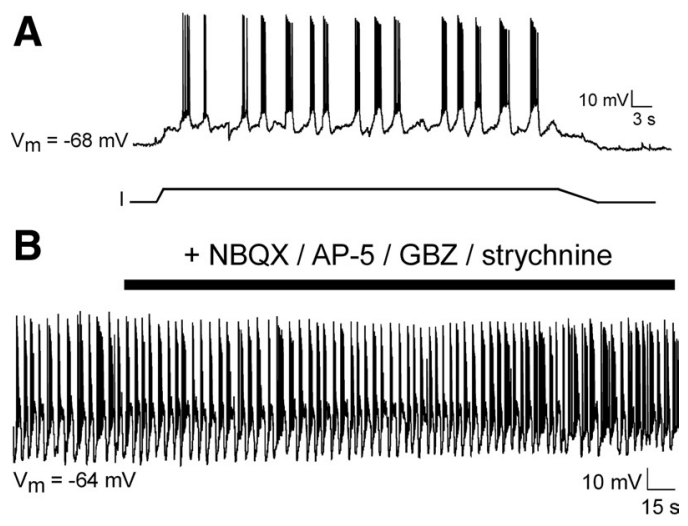

C

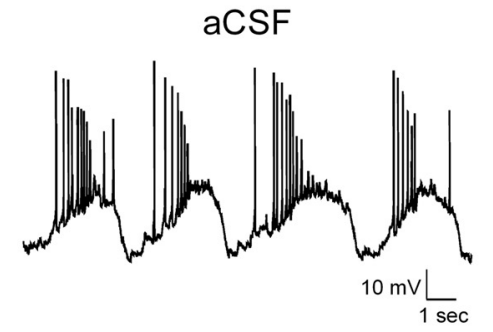

+ NBQX / AP-5 / GBZ / strychnine
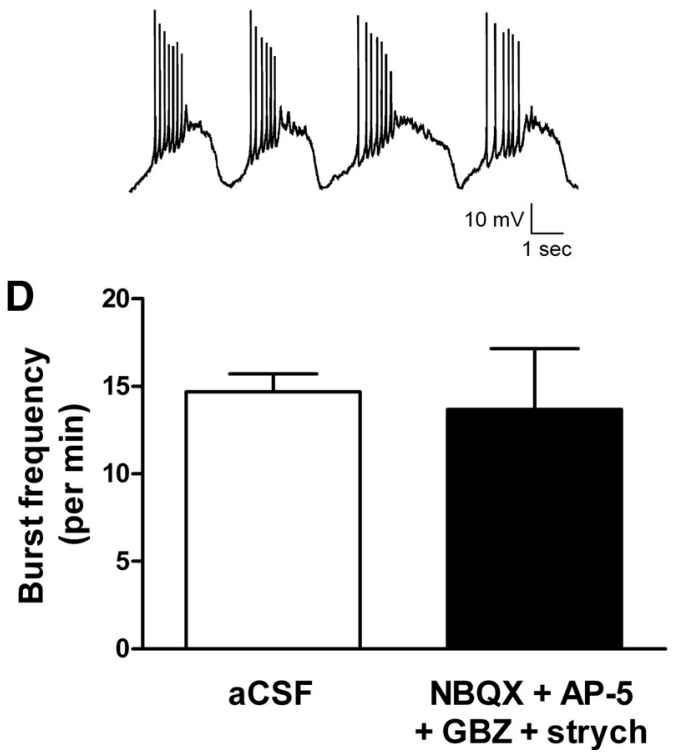

Figure 4. Pacemaker properties, not recurrent synaptic connections, drive rhythmic burst firing in neonatal lamina I neurons. $\boldsymbol{A}$, Membrane depolarization via direct current injection recruits burst firing in a previously silent lamina I neuron at $\mathrm{P}$, which disappears upon removal of the depolarizing current. $\boldsymbol{B}, \boldsymbol{C}$, The combined block of fast glutamatergic, GABAergic and glycinergic transmission does not affect the rhythmic burst firing. $\boldsymbol{D}$, Bath application of the antagonist mixture failed to change the mean burst frequency in bursting lamina I neurons at P2-P3 ( $n=6 ; p=1.0$, Wilcoxon's signed-rank test). Error bars indicate SEM.

the CNS (Peña et al., 2004; Sheroziya et al., 2009). Therefore, we next asked whether voltage-gated $\mathrm{Na}^{+}$channels were involved in the generation of the underlying slow oscillations as well as the AP discharge observed at the peak of the plateau potential. Bath application of TTX $(500 \mathrm{nM})$, which blocks both transient $\left(I_{\mathrm{Na}, \mathrm{T}}\right)$ and persistent $\left(I_{\mathrm{Na}, \mathrm{P}}\right)$ subtypes of $\mathrm{Na}^{+}$current in CNS neurons, completely eliminated the rhythmic activity in all lamina I neurons examined at P3-P4 (Fig. 5A,B). Application of the anticonvulsant riluzole, which shows a greater selectivity for $I_{\mathrm{Na}, \mathrm{P}}$ over $I_{\mathrm{Na}, \mathrm{T}}$ (Urbani and Belluzzi, 2000), also significantly reduced burst generation (Fig. 5C,D), which was accompanied by a decrease in the mean AP frequency within the burst $(\mathrm{aCSF}, 4.49 \pm 0.51 \mathrm{~Hz}$; RIL, $2.83 \pm 0.48 \mathrm{~Hz} ; n=9 ; p=0.008$, Wilcoxon's signed-rank test). To determine whether this reflected a general blockade of AP discharge by riluzole, we examined the effects of riluzole on the properties of APs evoked by direct current injection through the patch electrode in a subset of bursting neurons (Fig. 5E,F). Despite silencing the spontaneous bursting, riluzole failed to significantly affect the rheobase (aCSF, $17.9 \pm 4.3$ pA; RIL, $24.6 \pm$ $4.2 \mathrm{pA} ; n=7 ; p=0.172$, Wilcoxon's signed-rank test) as well as AP threshold (aCSF, $-41.5 \pm 1.7 \mathrm{mV}$; RIL, $-42.1 \pm 2.0 \mathrm{mV}$ ), amplitude (aCSF, $51.0 \pm 1.3 \mathrm{mV}$; RIL, $50.3 \pm 2.0 \mathrm{mV}$ ), rise time (aCSF, $1.99 \pm 0.15 \mathrm{~ms}$; RIL, $1.97 \pm 0.17 \mathrm{~ms}$ ), or half-width (aCSF, $2.79 \pm 0.19 \mathrm{~ms}$; RIL, $2.86 \pm 0.22 \mathrm{~ms}$ ). These results suggest that persistent $\mathrm{Na}^{+}$currents play a critical role in triggering the slow plateau potentials that underlie the intrinsic burst firing within lamina I of the neonatal SDH.

Given that bursting cells exhibit significantly higher membrane resistance compared with adjacent, nonbursting lamina I neurons (Fig. $1 F$ ), the above data also raise the possibility that spinal pacemaker neurons are distinguished by a high level of persistent $\mathrm{Na}^{+}$conductance $\left(g_{\mathrm{Na}, \mathrm{P}}\right)$ relative to the amount of leak membrane conductance $\left(g_{\text {leak }}\right)$, as has been previously demonstrated in bursting neurons within the respiratory brainstem (Del Negro et al., 2002). To examine this issue, following the classification of spontaneous firing pattern, voltage-clamp experiments were performed (see Materials and Methods) in which lamina I neurons were slowly depolarized from -110 to $-10 \mathrm{mV}$ (at a rate of $30 \mathrm{mV} / \mathrm{s}$ to promote the inactivation of fast $\mathrm{Na}^{+}$channels) in the presence of aCSF. TTX was then used to isolate the persistent $\mathrm{Na}^{+}$current (Fig. $6 A-C$ ), which activated at approximately -60 $\mathrm{mV}$ and peaked at -45 to $-40 \mathrm{mV}$, which is consistent with previous studies of $I_{\mathrm{Na}, \mathrm{P}}$ in adult lamina I neurons (Prescott and De Koninck, 2005). Importantly, when riluzole (10 $\mu \mathrm{M})$ was substituted for TTX (Fig. 6D), a current with similar voltagedependent properties was isolated (TTX: $V_{1 / 2}=-51.2 \pm 0.6 \mathrm{mV}$, $k=3.7 \pm 0.2, n=22$; RIL: $V_{1 / 2}=-50.2 \pm 1.0 \mathrm{mV}, k=4.1 \pm 0.4$, $n=7 ; p>0.30$, Mann-Whitney test), which supports the notion that riluzole acted on $I_{\mathrm{Na}, \mathrm{P}}$ to reduce spontaneous burst firing in neonatal lamina I neurons (Fig. $5 C, D$ ).

As illustrated in Figure 7, $A$ and $B$, the level of persistent $\mathrm{Na}^{+}$ current in bursting neurons was not significantly different from that in adjacent, nonbursting cells within lamina I, as measured either by the density of $I_{\mathrm{Na}, \mathrm{P}}$ (bursting: $0.84 \pm 0.09 \mathrm{pA} / \mathrm{pF}, n=8$; nonbursting: $0.76 \pm 0.08 \mathrm{pA} / \mathrm{pF}, n=18 ; p=0.76$, Mann-Whitney test) or the maximal conductance (bursting, $g_{\mathrm{Na}, \mathrm{P}}=0.22 \pm$ $0.03 \mathrm{nS}$; nonbursting, $\left.g_{\mathrm{Na}, \mathrm{P}}=0.24 \pm 0.03 \mathrm{nS} ; p=0.978\right) . I_{\mathrm{Na}, \mathrm{P}}$ also showed a similar voltage dependence in bursting $\left(V_{1 / 2}=\right.$ $-50.6 \pm 0.9 \mathrm{mV} ; k=4.2 \pm 0.3 ; n=6)$ and nonbursting $\left(V_{1 / 2}=\right.$ $-51.4 \pm 0.7 \mathrm{mV} ; k=3.6 \pm 0.2 ; n=16)$ neurons. The expression of $I_{\mathrm{Na}, \mathrm{P}}$ was significantly higher in spontaneously active cells $(0.26 \pm 0.02 \mathrm{nS} ; n=21)$ compared with silent lamina I neurons $(0.14 \pm 0.04 \mathrm{nS} ; n=5 ; p=0.023$, Mann-Whitney test) (Fig. 7C), suggesting that $I_{\mathrm{Na}, \mathrm{P}}$ alone may be a better predictor of spontaneous firing than of bursting per se. However, as predicted from our previous findings (Fig. $1 F$ ), bursting neurons did exhibit a significantly lower leak conductance $\left(g_{\text {leak }}\right)$ compared with nonbursting cells (bursting, $0.42 \pm 0.03 \mathrm{nS}$; nonbursting, $0.67 \pm 0.05 \mathrm{nS}$; $p=0.0004$, Mann-Whitney test) (Fig. 7D). As a result, calculating the ratio of $g_{\mathrm{Na}, \mathrm{P}} / g_{\text {leak }}$ for each neuron demonstrated that bursting was associated with significantly higher ratios (bursting, $0.53 \pm 0.03$; nonbursting, $0.36 \pm 0.04 ; p=0.005$ ) (Fig. $7 E, F)$. 
Overall, these results suggest that the combination of persistent, voltage-gated $\mathrm{Na}^{+}$currents and high membrane resistance (i.e., low $g_{\text {leak }}$ ) promotes rhythmic burst firing in a subset of lamina I neurons within the neonatal spinal cord. Notably, the membrane resistance of the overall population of lamina I neurons was significantly higher at P2-P3 (2253 \pm 307 $\mathrm{M} \Omega ; n=62$ ) than at later ages (P9-P10: $1249 \pm 207 \mathrm{M} \Omega, n=59 ; \mathrm{P} 20-\mathrm{P} 23$ : $1410 \pm 281 \mathrm{M} \Omega, n=42 ; p<0.0001$, Kruskal-Wallis test), suggesting that age-dependent changes in passive membrane properties might contribute to the observed decrease in the prevalence of burst firing during postnatal development (Fig. 1E).

$\mathrm{Ca}^{2+}$ influx via high-threshold VGCCs enhances burst firing in neonatal lamina I neurons

Rhythmic burst firing is also facilitated by transmembrane calcium $\left(\mathrm{Ca}^{2+}\right)$ influx via voltage-gated calcium channels (VGCCs), as bath perfusion of $\mathrm{CdCl}_{2}$ at a concentration $(500 \mu \mathrm{M})$ that is sufficient to block all known subtypes of VGCCs significantly reduced burst frequency in P2-P4 neurons (Fig. 8A,B). Since lamina I neurons have been previously shown to express both high-threshold ( $\mathrm{N}$-type and L-type) and low-threshold (T-type) VGCCs (Heinke et al., 2004), we next examined the effects of subtype-selective VGCC antagonists on burst firing in neonatal lamina I neurons. Bath application of the selective N-type VGCC antagonist $\omega$-CgTx $(1 \mu \mathrm{M})$ significantly reduced burst frequency (Fig. $8 D$ ) without altering the mean duration of the bursts (aCSF, $1.71 \pm$ $0.16 \mathrm{~s} ; \omega$-CgTx, $1.66 \pm 0.19 \mathrm{~s} ; n=7 ; p=0.688$, Wilcoxon's signed-rank test). $\omega$-CgTx appeared to cause a slight membrane depolarization and promote a switch from the bursting mode to single-spike discharge (Fig. 8C). Similar effects were observed following the block of L-type VGCCs with nifedipine (Fig. 8E), which also resulted in a significant decrease in the frequency (Fig. $8 F$ ) but not duration (aCSF, $1.57 \pm 0.20 \mathrm{~s}$; nifedipine, $1.51 \pm$ $0.33 s ; n=7 ; p=0.875)$ of the bursts. In contrast, perfusion with the selective T-type VGCC antagonist NNC 55-0396 (50 $\mu \mathrm{M})$ failed to alter either burst frequency (Fig. 8G,H) or duration (aCSF, $1.41 \pm 0.18 \mathrm{~s}$; NNC 55-0396, $1.26 \pm 0.09 \mathrm{~s} ; n=6 ; p=$ 0.688). Collectively, the results demonstrate that $\mathrm{Ca}^{2+}$ entry through high-threshold VGCCs are involved in the spontaneous burst firing of lamina I cells during early life.

\section{Intracellular $\mathrm{Ca}^{2+}$ signaling contributes to burst generation in neonatal lamina I neurons}

$\mathrm{Ca}^{2+}$ entry through VGCCs could contribute to the bursting by producing membrane depolarization and/or triggering the downstream activation of other channels or intracellular signaling pathways. To distinguish between these possibilities, we examined the prevalence of spontaneous burst firing within lamina I at P2-P3 when the high-affinity $\mathrm{Ca}^{2+}$ chelator BAPTA (15 mM) was included in the patch solution. BAPTA significantly reduced

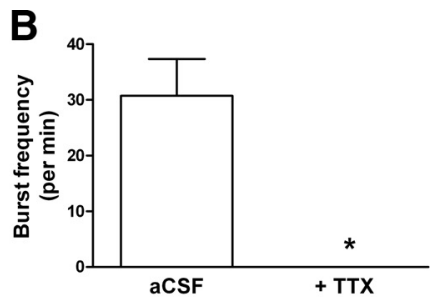

D

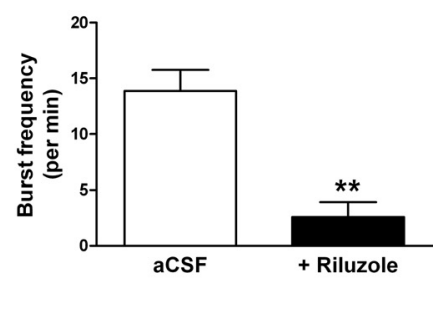

$\mathbf{F}$

+ Riluzole

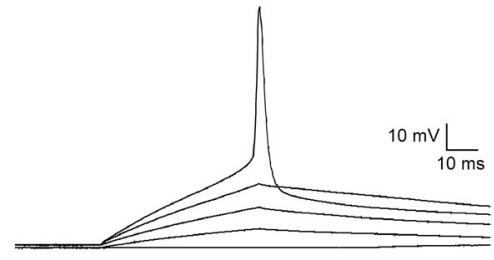
the fast spiking seen in aCSF (inset; calibration: $5 \mathrm{mV}, 1$ s) were both abolished by the bath application of $500 \mathrm{~nm} \operatorname{TTX}\left(n=5 ;{ }^{*} p<\right.$ Pilus , Wicoxon's signed-rank test) to block transient $\left(I_{\mathrm{Na}, \mathrm{T}}\right)$ and persistent $\left(I_{\mathrm{Na}, \mathrm{P}}\right)$ subtypes of voltage-gated $\mathrm{Na}^{+}$currents. $C, D$ P2-P3 ( $n=11 ;{ }^{* *} p=0.004$, Wilcoxon's test). Error bars indicate SEM. $\boldsymbol{E}, \boldsymbol{F}$, In contrast, riluzole did not significantly affect the properties of action potentials evoked by directly injecting current into bursting neurons via the patch electrode.

the percentage of lamina I cells that exhibited bursting compared with recordings obtained in the absence of exogenous intracellular $\mathrm{Ca}^{2+}$ buffers (Figs. $1 E, 9 A$ ). Since internal BAPTA should not interfere with the membrane depolarization produced by the $\mathrm{Ca}^{2+}$ influx, these results suggest that $\mathrm{Ca}^{2+}$ entry via VGCCs primarily contributes to rhythmic burst firing by initiating intracellular $\mathrm{Ca}^{2+}$ signaling.

In many types of rhythmically active neurons, $\mathrm{Ca}^{2+}$-activated $\mathrm{K}^{+}$currents $\left(I_{\mathrm{K}, \mathrm{Ca}}\right)$ underlie the afterhyperpolarization (AHP) that follows the burst discharge, and blocking these currents can abolish burst firing by preventing membrane repolarization and thus likely promoting the inactivation of voltage-gated $\mathrm{Na}^{+}$ channels (Bal and McCormick, 1993; Beurrier et al., 1999). The slight membrane depolarization and apparent reduction in AHPs within bursting lamina I neurons after $\omega$-CgTx (Fig. 8C, arrows) or nifedipine application suggested the possibility that the highthreshold VGCC antagonists reduced burst frequency in part by suppressing downstream $I_{\mathrm{K}, \mathrm{Ca}}$. If this was the case, one might predict that blocking $I_{\mathrm{K}, \mathrm{Ca}}$ directly would evoke a similar decrease in spontaneous burst firing within newborn lamina I cells. To further investigate this issue, a mixture containing TEA (1 mM) and apamin $(200 \mathrm{nM})$ was bath-applied to bursting neurons to block both large-conductance (BK) and small-conductance (SK) $\mathrm{Ca}^{2+}$-activated $\mathrm{K}^{+}$channels (Sah, 1996). The mixture significantly reduced burst firing in the majority of neurons examined (four of six), either by causing a persistent depolarization of the membrane $(n=2)$ (Fig. 9B) similar to that described previously in subthalamic neurons (Beurrier et al., 1999) or by promoting a 

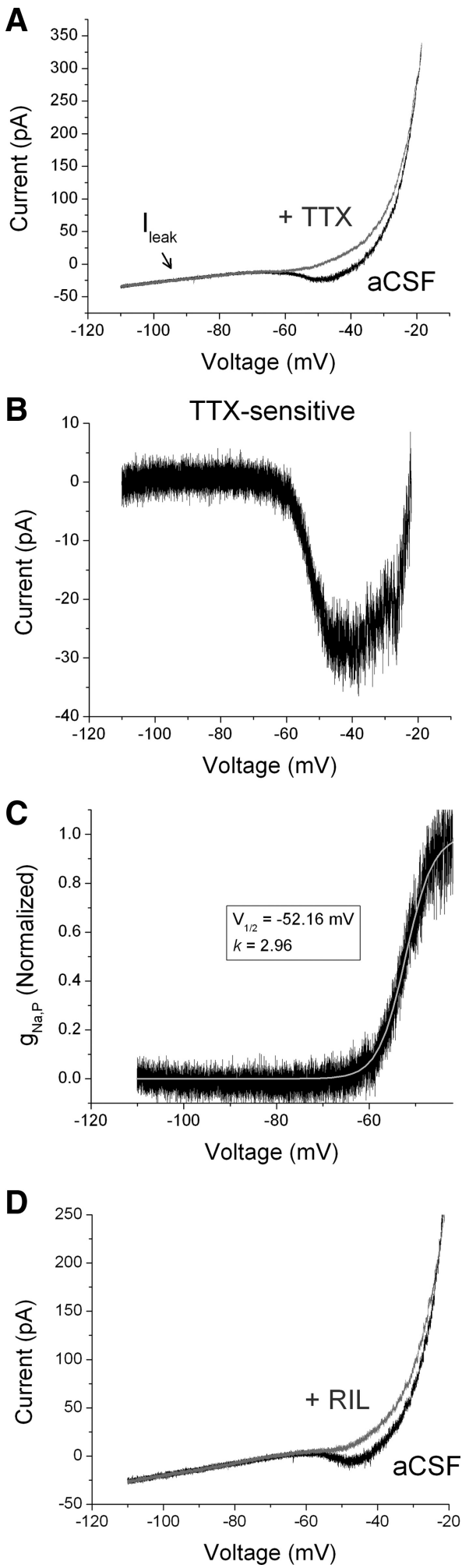

Figure 6. Isolation of persistent, voltage-gated $\mathrm{Na}^{+}$currents in lamina I neurons. $A, I-V$ relationship of currents evoked by a voltage ramp $(-100$ to $-10 \mathrm{mV}$ at $30 \mathrm{mV} / \mathrm{s})$ administered before (aCSF; black trace) and after (TTX; gray) the bath application of TTX. Leak current $\left(I_{\text {leak }}\right)$ was estimated from the linear portion of the trace between -110 and $-70 \mathrm{mV}$. $\boldsymbol{B}$, The TTXsensitive component was isolated by electronically subtracting the $I-V$ relationship observed in the presence of TTX from that seen in aCSF (same cell as in $\boldsymbol{A}$ ). $\boldsymbol{C}$, Example of the normalized conductance $\left(g_{\mathrm{Na}, \mathrm{P}} / g_{\mathrm{Na}, \mathrm{P} \text { max }}\right)$ plotted as a function of membrane voltage and fitted with a Boltzmann function (see Materials and Methods). D, The application of riluzole (10 $\mu \mathrm{m})$ produced similar effects on the evoked ramp currents as was observed using TTX treatment.
A

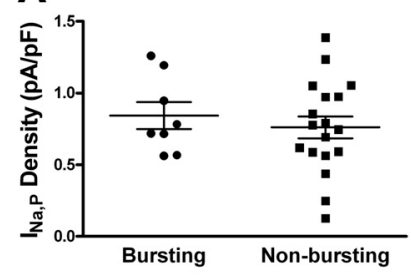

C

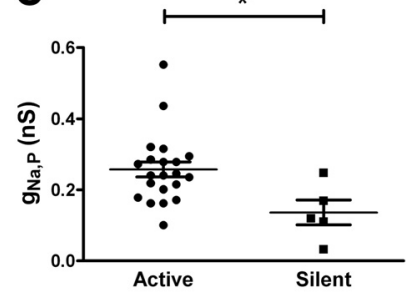

E

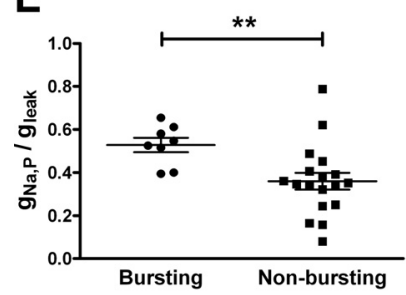

B

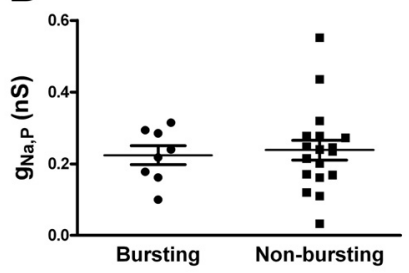

D

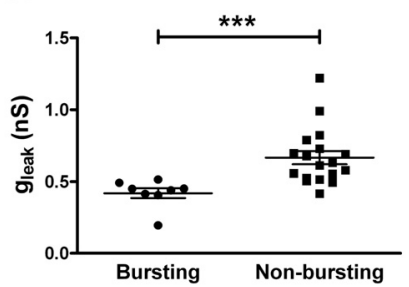

$\mathbf{F}$

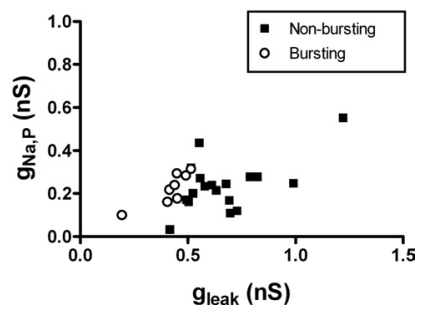

Figure 7. Pacemaker neurons exhibit a higher ratio of persistent $\mathrm{Na}^{+}$versus leak conductance. $\boldsymbol{A}, \boldsymbol{B}$, Bursting neurons exhibited a similar density $(\boldsymbol{A})$ and maximal conductance $(\boldsymbol{B})$ of persistent $\mathrm{Na}^{+}$current as adjacent, nonbursting neurons within lamina I at P2-P3. C, In contrast, the overall population of spontaneously firing cells (i.e., tonic, irregular, and bursting) showed a significantly greater persistent $\mathrm{Na}^{+}$conductance $\left(g_{\mathrm{Na}, \mathrm{P}}\right)$ compared with silent neurons at this age $\left({ }^{*} p=0.023\right.$, Mann-Whitney test). $\boldsymbol{D}$, Bursting neurons were distinguished by a lower leak conductance $\left(g_{\text {leak }}\right)$ compared with nonbursting neurons ( ${ }^{* * *} p=0.0004$, MannWhitney test). $\boldsymbol{E}$, The ratio of persistent $\mathrm{Na}{ }^{+}$to leak conductance $\left(g_{\mathrm{Na}, \mathrm{p}} \mathrm{p} / g_{\text {leak }}\right)$ in a given neuron was significantly higher within the bursting group compared with nonbursters $\left({ }^{* *} p=0.005\right.$, Mann-Whitney test). $\boldsymbol{F}$, Individual bursting $(\bigcirc)$ and nonbursting $(\square)$ lamina I cells were plotted as a function of $g_{\mathrm{Na}, \mathrm{P}}$ and $g_{\text {leak }}$ illustrating that the bursting cells cluster at lower levels of leak conductance.

switch to high-frequency tonic firing $(n=2)$ (Fig. 9C). The remaining neurons $(n=2)$ exhibited bursts of unusually prolonged duration (6-15 s) in aCSF that were unaffected by blocking $I_{\mathrm{K}, \mathrm{Ca}}$ (data not shown), suggesting that other ionic mechanisms may underlie the termination of burst discharge in these neurons. Further experiments are required to determine which specific subtypes of $I_{\mathrm{K}, \mathrm{Ca}}$ are critically involved in the generation of pacemaker activity within the developing dorsal horn.

Another downstream target of intracellular $\mathrm{Ca}^{2+}$ signaling pathways, the $\mathrm{Ca}^{2+}$-activated nonselective cationic current $\left(I_{\text {CAN }}\right)$, is a promising candidate to contribute to the slow oscillations since it does not inactivate in the presence of elevated $\left[\mathrm{Ca}^{2+}\right]_{\text {int }}$ (Partridge et al., 1994) and drives plateau potentials in other CNS neurons (Sheroziya et al., 2009) including DDH neurons of the adult spinal cord (Morisset and Nagy, 1999). We examined a potential role for $I_{\mathrm{CAN}}$ in the burst firing of lamina I neurons by bath-applying the nonselective antagonist FFA at P2-P3 $(n=4)$. In two neurons exhibiting relatively weak bursting, FFA blocked action potential discharge during the plateau phase but did not abolish the underlying oscillations of membrane potential (Fig. 10A). In two neurons showing robust burst firing, FFA reduced the duration of the plateau potentials and 
promoted the occurrence of doublets or shortened periods of spiking (Fig. $10 \mathrm{~B}$, arrows). A reduction in the amount of time spent at the peak of the plateau potential in the presence of FFA was also apparent from the diminution of the second peak in the membrane potential histogram (Fig. $10 C, D)$. Although the development of more specific antagonists is needed to conclusively address this issue, the available evidence is consistent with a potential role for $I_{\mathrm{CAN}}$ in the spontaneous burst firing present in lamina I during early life.

Pacemaker neurons transmit input from high-threshold sensory afferents with poor fidelity

To classify the pattern of sensory input onto bursting lamina I neurons during the neonatal period, we recorded evoked EPSCs in these cells in response to electrical stimulation of the attached dorsal root (DR). In all cases examined $(n=6)$, the bursting neurons selectively received synaptic input from high-threshold primary afferents (Fig. 11A), which was classified as monosynaptic based on the absence of failures during repetitive stimulation (Fig. 11B).

Previous studies using the dynamicclamp method have shown that pharmacologically induced rhythmic burst firing disrupts the input-output relationship in adult DDH neurons following the activation of artificial nociceptive inputs (Derjean et al., 2003). To determine whether the spontaneous burst firing in newborn lamina I neurons also results in a poor fidelity of signal transmission, we qualitatively examined the responses of these neurons to primary afferent stimulation at different stages of the bursting process under current-clamp conditions. Highthreshold DR stimulation delivered during the period between spontaneous bursts could evoke a plateau potential with prolonged AP discharge (Fig. 11C,D, point 1). However, this depended on the temporal relationship between the afferent input and the termination of the preceding burst, as the same DR stimulation applied immediately following a burst failed to evoke a plateau potential (Fig. 11C,D, point 3). Meanwhile, DR stimulation occurring during a spontaneous burst produced highly variable effects on the level of postsynaptic output. In some cases, the sensory input evoked little AP discharge and in fact appeared to abruptly truncate the plateau potential (Fig. $11 C, D$, point 2), likely via the activation of a polysynaptic inhibitory pathway, while during other bursts only a slight increase in the intraburst frequency was observed following DR stimulation (data not shown). In contrast, when the same bursting neuron was silenced by directly injecting hyperpolarizing current through the patch electrode, a more stable input-output relationship was noted (Fig. 11E). Therefore, our results support the idea that oscillatory burst firing can interfere with the faithful transfer of nociceptive signals within the spinal dorsal horn (Derjean et al., 2003).

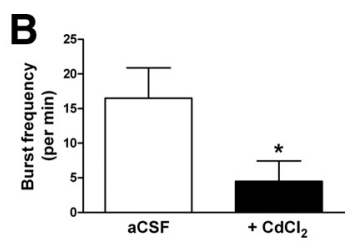

D

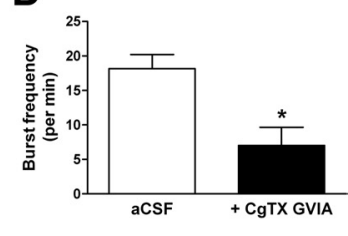

$\mathbf{F}$

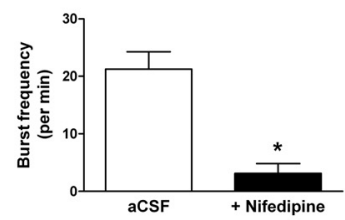

H

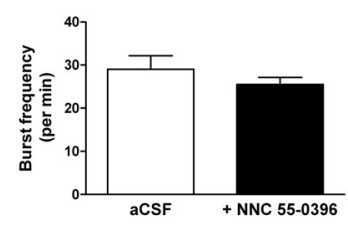

Figure 8. N-type and L-type VGCCs contribute to rhythmic burst firing in lamina I during early life. $A, B$, Burst frequency was significantly reduced following the block of all subtypes of $\mathrm{VGCC}$ with $\mathrm{CdCl}_{2}\left(n=6 ;{ }^{*} p=0.036\right.$, Wilcoxon's signed-rank test). $C$ and decreased the burst frequency $\left(n=7 *^{*} p=0.031\right)$. F F S Similar effects were observed after blocking L-type VGCCs with nifedipine $\left(n=7 ;{ }^{*} p=0.016\right) . \mathbf{G}, \boldsymbol{H}$, The administration of the selective T-type VGCC antagonist NNC 55-0396 failed to influence spontaneous burst firing in immature lamina I neurons $(n=6 ; p=0.202)$. Error bars indicate SEM.

\section{Discussion}

These results demonstrate, for the first time, that a significant number of pacemaker neurons are present within spinal pain circuits during early life. Intrinsic, oscillatory burst firing was restricted to lamina I of the SDH and downregulated after the first postnatal week, which agrees with previous reports that spontaneous bursting is very rarely observed in the mature dorsal horn (Jiang et al., 1995; Derjean et al., 2003). The rhythmic burst firing was associated with a high ratio of persistent, voltage-gated $\mathrm{Na}^{+}$ to leak membrane conductance and was facilitated by $\mathrm{Ca}^{2+}$ influx via high-threshold VGCCs. The data collectively suggest that the population of bursting neurons is composed at least partly of glutamatergic interneurons that project to the $\mathrm{SDH}$, deep dorsal horn, and the ventral horn. These pacemaker neurons are innervated by high-threshold primary afferents, consistent with their potential role in spinal nociceptive processing, but did not reliably convey sensory input when it coincided with the plateau phase of the bursting cycle.

\section{Identification of pacemaker neurons within the developing SDH}

Our results suggest that the population of pacemakers within lamina I of the neonate does not include the ascending projection neurons (Fig. $2 C, D$ ). Therefore, while a considerable fraction of spino-PAG neurons exhibits burst firing in response to intracellular current injection at P20-P26 (Ruscheweyh et al., 2004), these cells do not appear to spontaneously burst during the neo- 
A

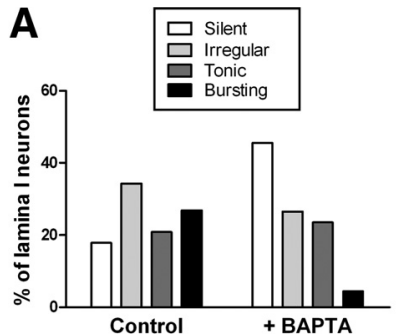

C aCSF

$+1 \mathrm{mM}$ TEA $200 \mathrm{nM}$ apamin

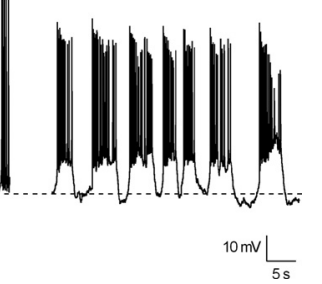

Figure 9. Intracellular $\mathrm{Ca}^{2+}$ signaling contributes to rhythmic burst firing in lamina I during the neonatal period. $\boldsymbol{A}$, The prevalence of burst firing within lamina I at P2-P3 was significantly reduced by the inclusion of the high-affinity $\mathrm{Ca}^{2+}$ chelator BAPTA in the pipette $(n=68 ; p<$ $0.001, \chi^{2}$ test) compared with the control (i.e., lacking exogenous $\mathrm{Ca}^{2+}$ buffers) intracellular solution (data replotted from Fig. $1 E$, left). $\boldsymbol{B}$, Bath application of a mixture to block BK- and SK-type $I_{K, C_{a}}$ reversibly interferes with burst repolarization and suppresses firing in a subset of pacemaker neurons within lamina I. C, The same antagonist mixture could evoke a switch to single spike discharge in another population of bursting neurons.
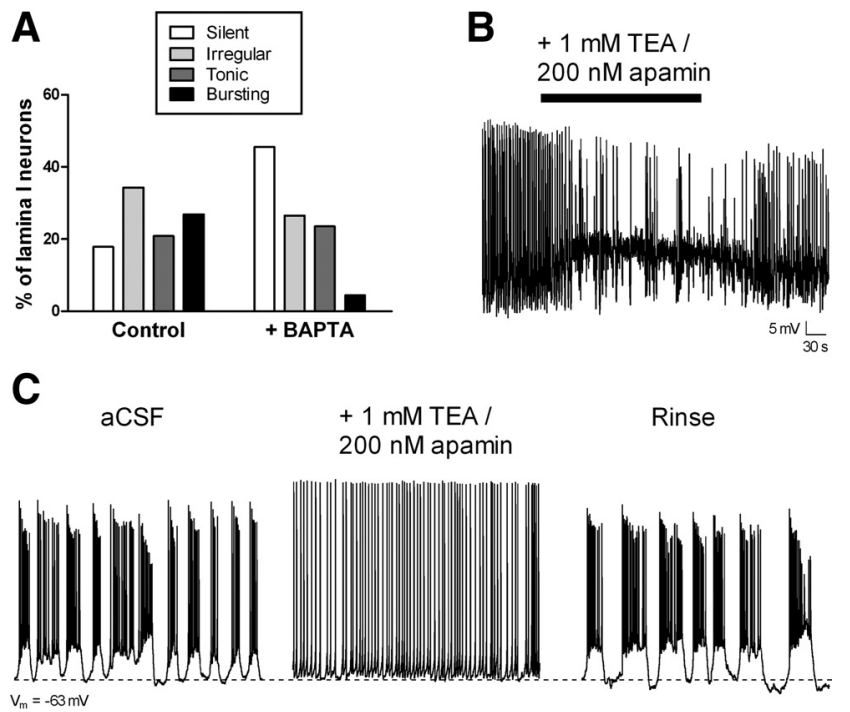

natal period. Although we cannot completely exclude the possibility that lamina I neurons projecting to the lateral thalamus or caudal ventrolateral medulla can generate rhythmic burst firing, this seems unlikely since the vast majority of these neurons send collaterals to the parabrachial nucleus and therefore should have been sampled in our experiments (Hylden et al., 1989; Spike et al., 2003). In addition, while lamina I neurons projecting to the brain via the anterolateral tract have been reported to be large in diameter, possess relatively low membrane resistance, and send axon collaterals to laminae V-VII of the spinal cord (Luz et al., 2010; Szucs et al., 2010), pacemaker neurons are characterized by their small size, high membrane resistance (Fig. $1 F$ ), and the presence of axonal terminations within deeper laminae in the ventral horn (Fig. 3C). However, since the genesis of supraspinal projection neurons occurs before the birth of propriospinal neurons and local circuit interneurons (Bice and Beal, 1997a,b), it is feasible that rhythmic burst firing does occur within projection neurons during the embryonic period and is subsequently downregulated by birth.

Two lines of evidence support the notion that glutamatergic lamina I neurons are capable of rhythmic burst firing during the neonatal period. First, axonal boutons from identified pacemaker neurons in the rat spinal cord demonstrated immunoreactivity for the vesicular glutamate transporter VGLUT2 (Fig. 3D-F). In addition, burst firing appeared restricted to the non-GFP population of SDH neurons in newborn Gad-GFP mice (Fig. $3 H$ ). It remains possible that the fraction of non-GFP neurons exhibiting bursting corresponds to either a subpopulation of GABAergic neurons that fails to express GFP or to a group of glycinergic neurons within the SDH. While glycinergic neurons within
A

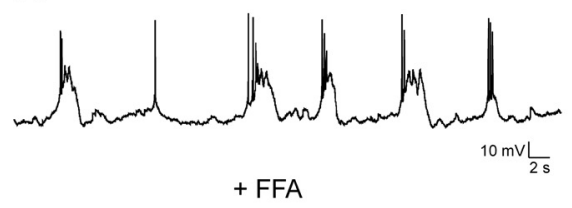

B

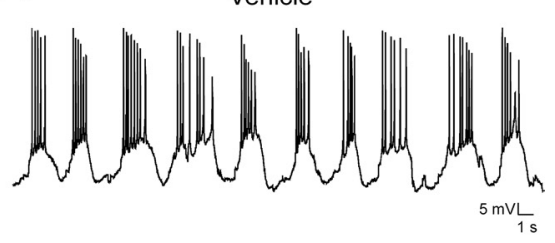

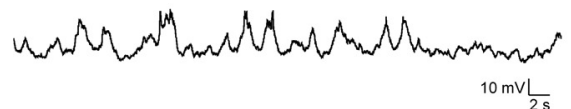
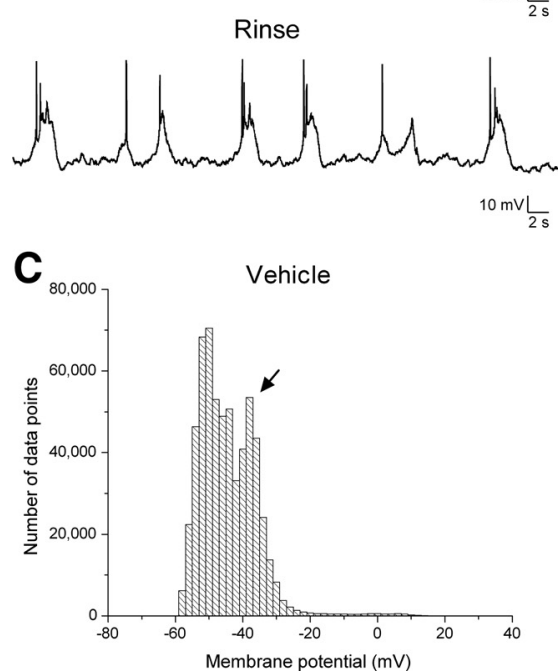
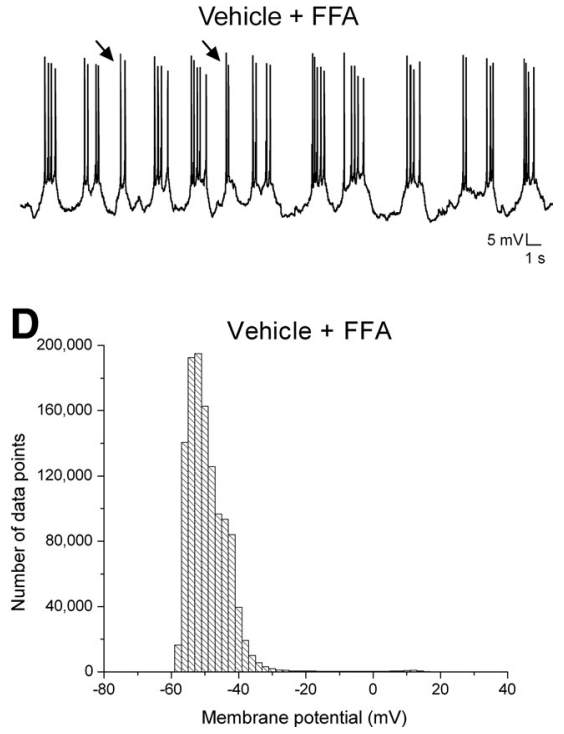

Figure 10. Potential role for $I_{\text {CAN }}$ in pacemaker activity within the developing SDH. $A$, Application of FFA (200 $\mu$ M) to a weakly bursting lamina I neuron reversibly blocked action potential discharge but did not abolish the underlying oscillations. $\boldsymbol{B}$, In neurons exhibiting more robust spontaneous burst firing, FFA decreased the duration of the plateau potentials and promoted the appearance of spike doublets (arrows). C, D, All-points histograms of the membrane potential (not corrected for liquid junction potentials) in the presence of the vehicle solution ( $0.1 \%$ DMSO) or FFA in the same lamina I neuron at P3. Note the loss of the second peak (C, arrow), suggesting a reduction in the amount of time the neuron spends at the depolarized level of the plateau potential in the presence of FFA. the rat SDH constitute a subset of the GABAergic population (Todd and Sullivan, 1990), this relationship has not been conclusively demonstrated in the developing mouse dorsal horn. Nonetheless, coexpression of these neurotransmitters seems likely since the same transcription factors promote GABAergic and glycinergic fates in the mouse SDH (Huang et al., 2008). Therefore, we expect that glycinergic neurons were sampled as part of the Gad-GFP group, which showed no evidence of rhythmic bursting during the first days of life (Fig. 3H). However, plateau potentials have been identified in GABAergic lamina I neurons at later ages (Dougherty and Hochman, 2008).

\section{Ionic mechanisms driving rhythmic burst firing in spinal nociceptive networks}

The results suggest that the expression of persistent, voltage-gated $\mathrm{Na}^{+}$currents $\left(I_{\mathrm{Na}, \mathrm{P}}\right)$ combined with a low level of leak conductance (i.e., high membrane resistance) promotes spontaneous burst firing within developing lamina I neurons (Figs. 5-7). The appearance of slow plateau potentials at membrane potentials between -65 and $-50 \mathrm{mV}$ is consistent with the voltage dependence of $I_{\mathrm{Na}, \mathrm{P}}$ in lamina I neurons as described here (Fig. 6) and 
A
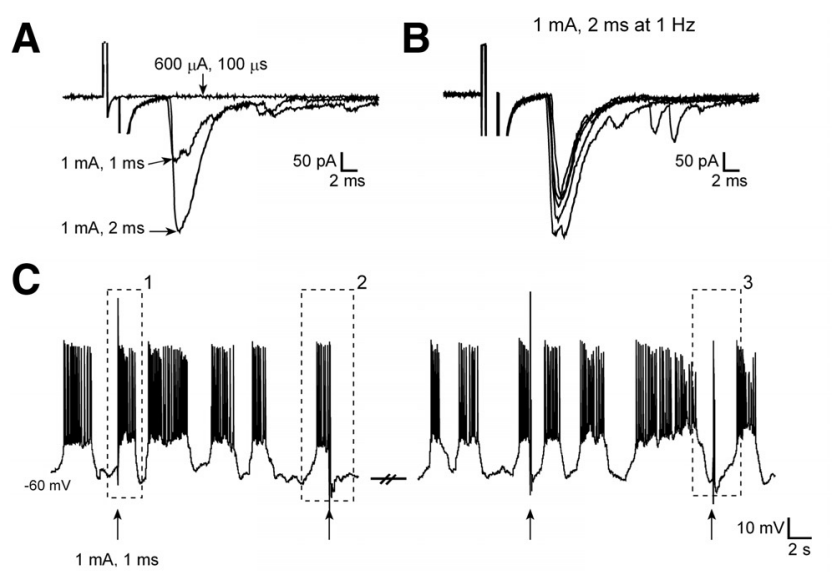

D

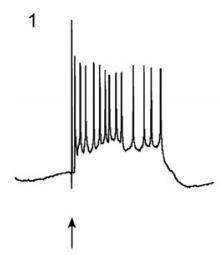

2
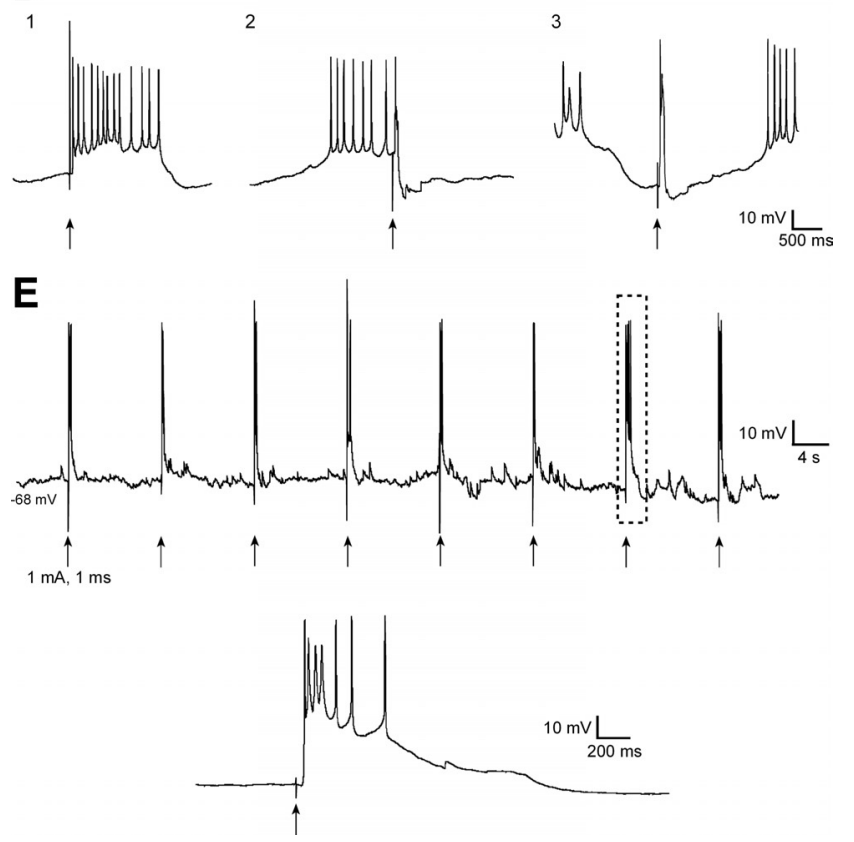

Figure 11. Pacemaker neurons convey monosynaptic input from high-threshold primary afferents with low fidelity during the bursting mode. $\boldsymbol{A}$, Voltage-clamp recording illustrating examples of the EPSCs evoked by DR stimulation in a bursting lamina I neuron at P2-P3. Stimulation of the DR at an intensity $(600 \mu \mathrm{A}, 100 \mu \mathrm{s})$ that is sufficient to activate all lowthreshold A-fiber inputs failed to evoke an EPSC in any of the bursting neurons examined ( $n=$ 6), while high-threshold (HT) stimulation consistently recruited a synaptic response which was classified as monosynaptic based on its ability to follow repetitive stimulation $(\boldsymbol{B})$. $\boldsymbol{C}, \boldsymbol{D}$, The delivery of HT stimuli (1 mA, $1 \mathrm{~ms}$ ) to the DR during different phases of the spontaneous burst firing within a single neuron (arrows) suggests that the relationship between afferent input and spike output in immature lamina I cells is disrupted by the presence of rhythmic bursting. $\boldsymbol{E}$, Top, The sensory input appeared more faithfully transmitted in the same neuron when the spontaneous burst firing was removed via direct membrane hyperpolarization (see bottom for example of afferent-evoked burst discharge).

previously (Prescott and De Koninck, 2005). Previous work has shown that the $\mathrm{Na}_{\mathrm{v}} 1.3$ and $\mathrm{Na}_{\mathrm{v}} 1.6$ subunits can generate $I_{\mathrm{Na}, \mathrm{P}}$ (Goldin, 1999) and are maximally expressed in the neonatal spinal cord (Beckh et al., 1989; Felts et al., 1997). In particular, $\mathrm{Na}_{\mathrm{v}} 1.3$ channels exhibit multiple properties that are conducive to the generation of oscillatory burst firing, as their decreased rate of closed-state inactivation allows for a more robust response to slow, subthreshold depolarizations, while their ability to rapidly recover from inactivation facilitates high-frequency spike discharge (Cummins et al., 2001).
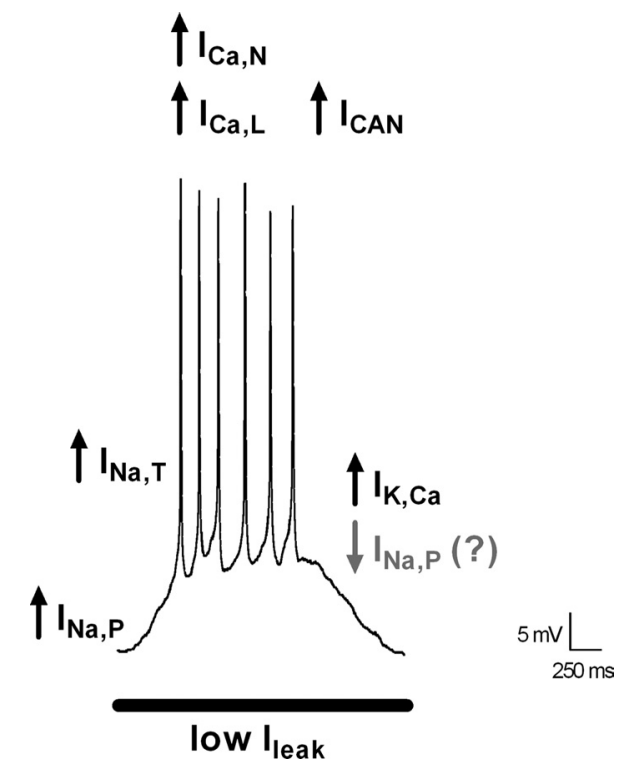

Figure 12. Summary of proposed ionic mechanisms underlying rhythmic burst firing in neonatal lamina I neurons. Persistent, voltage-gated $\mathrm{Na}^{+}$currents $\left(I_{\mathrm{Na}, \mathrm{P}}\right)$ activate near the resting membrane potential which, when accompanied by low leak conductance, evokes a slow plateau-like depolarization that triggers spike discharge via the fast $I_{\mathrm{Na}, \mathrm{T}}$. This evokes $\mathrm{Ca}^{2+}$ influx via high-threshold (N-type and L-type) voltage-gated $\mathrm{Ca}^{2+}$ channels that facilitates burst firing by (1) opening $\mathrm{Ca}^{2+}$-activated nonselective cation channels $\left(I_{\text {CAN }}\right)$ and $(2)$ driving $\mathrm{Ca}^{2+}$-activated $\mathrm{K}^{+}$currents $\left(I_{\mathrm{K}, \mathrm{Ca}}\right)$ to promote afterhyperpolarization and the subsequent repriming of voltage-gated $\mathrm{Na}^{+}$channels. Modeling studies of bursting neurons in the respiratory network have suggested that the slow inactivation of $I_{\mathrm{Na}, \mathrm{P}}$ may be important for burst termination (Del Negro et al., 2002), although this has not yet been tested in pacemaker neurons within lamina I of the newborn spinal cord (gray).

While it is clear that pacemaker neurons differ from adjacent, nonbursting lamina I cells in terms of leak conductance, little is known about the molecular basis for these background currents in the developing SDH. Recent work suggests that two-poredomain $\mathrm{K}^{+}$(KCNK) channels strongly regulate neuronal excitability in many areas of the CNS and can be modulated by a variety of factors such as neurotransmitters, $\mathrm{pH}$, or anesthetics. However, leak currents may also be attributable to any channel open at rest, including (but not limited to) inward-rectifying $\mathrm{K}^{+}$ channels $\left(\mathrm{K}_{\mathrm{ir}}\right)$, voltage-gated $\mathrm{K}^{+}\left(\mathrm{K}_{\mathrm{v}}\right)$ channels, or KCNQ channels underlying the $\mathrm{M}$-type $\mathrm{K}^{+}$current (Goldstein et al., 2001). It will be important to examine the relative expression of these channels across different populations of SDH neurons during early development and determine whether the modulation of leak conductances can promote a switch between pacemaker and nonpacemaker modes of spontaneous activity.

$\mathrm{Ca}^{2+}$ influx and subsequent intracellular $\mathrm{Ca}^{2+}$ signaling are also important for spontaneous bursting in the immature SDH. Lamina I neurons are known to possess L-, N-, and T-type VGCCs, while blocking P/Q-type VGCCs does not affect postsynaptic $\mathrm{Ca}^{2+}$ responses in these cells (Heinke et al., 2004). While low-threshold (T-type) VGCCs mediate burst firing in DDH neurons of the adult turtle (Russo and Hounsgaard, 1996), we observed no effect of the selective T-type antagonist NNC 55-0396 (Huang et al., 2004) on pacemaker activity within the developing SDH. This is likely explained by the steady-state inactivation of T-type channels at the range of voltages where bursting is seen in neonatal lamina I neurons (Ryu and Randic, 1990). This voltage range is more consistent with a role for highthreshold N-type or L-type VGCCs (Dolphin, 1995), and the burst frequency in lamina I neurons was significantly reduced by 
both $\omega$-CgTx and nifedipine (Fig. 8). L-type VGCCs are also known to be critically involved in the generation of plateau potentials in adult rat DDH neurons, although the pacemaker neurons described here are distinguished by their spontaneous burst firing and failure to show the acceleration in firing rate and prolonged afterdischarge (Fig. $11 E$ ), which are hallmark features of mature lamina V neurons (Morisset and Nagy, 1999).

Collectively, the evidence suggests that rhythmic burst firing in newborn lamina I neurons results from the interaction of multiple active and passive ionic conductances (Fig. 12) rather than from the expression and/or gating of a single ion channel.

\section{Potential functional implications of pacemaker activity within lamina I during early life}

Mounting evidence suggests that the spinal circuitry responsible for the NWR is organized in a "modular" fashion, where reflex encoding neurons (REs) in the deep dorsal horn receive nociceptive input (either directly from primary afferents or from $\mathrm{SDH}$ cells) and transmit this information to motoneurons (MNs) to initiate the appropriate muscle contraction for limb withdrawal (Schouenborg, 2008). NWRs are poorly tuned at birth, as evidenced by their large, disparate receptive fields (Fitzgerald, 2005) and high error rate (i.e., movement toward the noxious stimulus), but demonstrate marked functional improvement during the early postnatal period, which depends on tactile sensory experience (Waldenström et al., 2003). It has been proposed that spontaneous burst firing in REs drives MN activity, producing a muscle twitch that causes skin movement and thus alters skin pressure, which in turn modulates sensory input to the dorsal horn and promotes activity-dependent synaptic reorganization (Petersson et al., 2003). In this context, the observation that at least some pacemaker neurons within lamina I send glutamatergic projections to the superficial and deep dorsal horn as well as the ventral horn raises the intriguing possibility that the rhythmic bursting could partly substitute for nociceptive input at early stages of development by providing an initial excitatory drive to the sensorimotor networks underlying the NWR, either by evoking firing in the REs or by facilitating spontaneous muscle contractions via direct synapses onto neurons within the spinal motor network.

The distinct properties of neonatal cutaneous reflexes may be explained by a variety of underlying factors such as an altered pattern of primary afferent input (Beggs et al., 2002) and spinal inhibitory networks that are poorly tuned (Bremner and Fitzgerald, 2008). However, the existence of spontaneously bursting neurons in the SDH whose activity is independent of sensory input might also be predicted to contribute to the observed mismatch between the nature and/or location of the sensory stimulus and the reflex behavior in neonates.

\section{References}

Adlard BP, Dobbing J, Smart JL (1973) An alternative animal model for the full-term small-for-dates human baby. Biol Neonate 23:95-108.

Al Ghamdi KS, Polgár E, Todd AJ (2009) Soma size distinguishes projection neurons from neurokinin 1 receptor-expressing interneurons in lamina I of the rat lumbar spinal dorsal horn. Neuroscience 164:1794-1804.

Altman J, Bayer SA (1995) Atlas of prenatal rat brain development. Boca Raton, FL: CRC.

Bal T, McCormick DA (1993) Mechanisms of oscillatory activity in guineapig nucleus reticularis thalami in vitro: a mammalian pacemaker. J Physiol 468:669-691.

Beckh S, Noda M, Lübbert H, Numa S (1989) Differential regulation of three sodium channel messenger RNAs in the rat central nervous system during development. EMBO J 8:3611-3616.

Beggs S, Torsney C, Drew LJ, Fitzgerald M (2002) The postnatal reorgani- zation of primary afferent input and dorsal horn cell receptive fields in the rat spinal cord is an activity-dependent process. Eur J Neurosci 16:1249-1258.

Beurrier C, Congar P, Bioulac B, Hammond C (1999) Subthalamic nucleus neurons switch from single-spike activity to burst-firing mode. J Neurosci 19:599-609.

Bice TN, Beal JA (1997a) Quantitative and neurogenic analysis of the total population and subpopulations of neurons defined by axon projection in the superficial dorsal horn of the rat lumbar spinal cord. J Comp Neurol 388:550-564.

Bice TN, Beal JA (1997b) Quantitative and neurogenic analysis of neurons with supraspinal projections in the superficial dorsal horn of the rat lumbar spinal cord. J Comp Neurol 388:565-574.

Bremner LR, Fitzgerald M (2008) Postnatal tuning of cutaneous inhibitory receptive fields in the rat. J Physiol 586:1529-1537.

Cummins TR, Aglieco F, Renganathan M, Herzog RI, Dib-Haji SD, Waxman SG (2001) Nav1.3 sodium channels: rapid repriming and slow closedstate inactivation display quantitative differences after expression in a mammalian cell line and in spinal sensory neurons. J Neurosci 21:5952-5961.

Del Negro CA, Koshiya N, Butera RJ Jr, Smith JC (2002) Persistent sodium current, membrane properties and bursting behavior of pre-Bötzinger complex inspiratory neurons in vitro. J Neurophysiol 88:2242-2250.

Derjean D, Bertrand S, Le Masson G, Landry M, Morisset V, Nagy F (2003) Dynamic balance of metabotropic inputs causes dorsal horn neurons to switch functional states. Nat Neurosci 6:274-281.

Dolphin AC (1995) The G.L. Brown Prize Lecture. Voltage-dependent calcium channels and their modulation by neurotransmitters and $\mathrm{G}$ proteins. Exp Physiol 80:1-36.

Dougherty KJ, Hochman S (2008) Spinal cord injury causes plasticity in a subpopulation of lamina I GABAergic interneurons. J Neurophysiol 100:212-223.

Dougherty KJ, Sawchuk MA, Hochman S (2009) Phenotypic diversity and expression of GABAergic inhibitory interneurons during postnatal development in lumbar spinal cord of glutamic acid decarboxylase 67-green fluorescent protein mice. Neuroscience 163:909-919.

Felts PA, Yokoyama S, Dib-Hajj S, Black JA, Waxman SG (1997) Sodium channel alpha-subunit mRNAs I, II, III, NaG, Na6 and hNE (PN1): different expression patterns in developing rat nervous system. Brain Res Mol Brain Res 45:71-82.

Fitzgerald M (2005) The development of nociceptive circuits. Nat Rev Neurosci 6:507-520.

Fitzgerald M, Jennings E (1999) The postnatal development of spinal sensory processing. Proc Natl Acad Sci U S A 96:7719-7722.

Fleidervish IA, Gutnick MJ (1996) Kinetics of slow inactivation of persistent sodium current in layer $\mathrm{V}$ neurons of mouse neocortical slices. J Neurophysiol 76:2125-2130.

Goldin AL (1999) Diversity of mammalian voltage-gated sodium channels. Ann N Y Acad Sci 868:38-50.

Goldstein SA, Bockenhauer D, O'Kelly I, Zilberberg N (2001) Potassium leak channels and the KCNK family of two-P-domain subunits. Nat Rev Neurosci 2:175-184.

Granmo M, Petersson P, Schouenborg J (2008) Action-based body maps in the spinal cord emerge from a transitory floating organization. J Neurosci 28:5494-5503.

Heinke B, Balzer E, Sandkühler J (2004) Pre- and postsynaptic contributions of voltage-dependent $\mathrm{Ca}^{2+}$ channels to nociceptive transmission in rat spinal lamina I neurons. Eur J Neurosci 19:103-111.

Hoorneman EM (1985) Stereotaxic operation in the neonatal rat; a novel and simple procedure. J Neurosci Methods 14:109-116.

Huang L, Keyser BM, Tagmose TM, Hansen JB, Taylor JT, Zhuang H, Zhang M, Ragsdale DS, Li M (2004) NNC 55-0396 [(1S,2S)-2-(2-(N-[(3-benzimidazol2-yl)propyl]- $N$-methylamino)ethyl)-6-fluoro-1,2, 3,4-tetrahydro-1-isopropyl2-naphtyl cyclopropanecarboxylate dihydrochloride]: a new selective inhibitor of T-type calcium channels. J Pharmacol Exp Ther 309:193-199.

Huang M, Huang T, Xiang Y, Xie Z, Chen Y, Yan R, Xu J, Cheng L (2008) Ptf1a, Lbx1 and Pax2 coordinate glycinergic and peptidergic transmitter phenotypes in dorsal spinal inhibitory neurons. Dev Biol 322:394-405.

Hylden JL, Anton F, Nahin RL (1989) Spinal lamina I projection neurons in the rat: collateral innervation of parabrachial area and thalamus. Neuroscience 28:27-37.

Jiang MC, Cleland CL, Gebhart GF (1995) Intrinsic properties of deep dor- 
sal horn neurons in the L6-S1 spinal cord of the intact rat. J Neurophysiol 74:1819-1827.

Katz LC, Shatz CJ (1996) Synaptic activity and the construction of cortical circuits. Science 274:1133-1138.

Koshiya N, Smith JC (1999) Neuronal pacemaker for breathing visualized in vitro. Nature 400:360-363.

Lorenzo LE, Ramien M, St Louis M, De Koninck Y, Ribeiro-da-Silva A (2008) Postnatal changes in the Rexed lamination and markers of nociceptive afferents in the superficial dorsal horn of the rat. J Comp Neurol 508:592-604.

Luz LL, Szucs P, Pinho R, Safronov BV (2010) Monosynaptic excitatory inputs to spinal lamina I anterolateral-tract-projecting neurons from neighbouring lamina I neurons. J Physiol 588:4489-4505.

Maxwell DJ, Belle MD, Cheunsuang O, Stewart A, Morris R (2007) Morphology of inhibitory and excitatory interneurons in superficial laminae of the rat dorsal horn. J Physiol 584:521-533.

Morisset V, Nagy F (1999) Ionic basis for plateau potentials in deep dorsal horn neurons of the rat spinal cord. J Neurosci 19:7309-7316.

Oliva AA Jr, Jiang M, Lam T, Smith KL, Swann JW (2000) Novel hippocampal interneuronal subtypes identified using transgenic mice that express green fluorescent protein in GABAergic interneurons. J Neurosci 20:3354-3368.

Partridge LD, Müller TH, Swandulla D (1994) Calcium-activated nonselective channels in the nervous system. Brain Res Brain Res Rev 19:319-325.

Peña F, Parkis MA, Tryba AK, Ramirez JM (2004) Differential contribution of pacemaker properties to the generation of respiratory rhythms during normoxia and hypoxia. Neuron 43:105-117.

Petersson P, Waldenström A, Fåhraeus C, Schouenborg J (2003) Spontaneous muscle twitches during sleep guide spinal self-organization. Nature 424:72-75.

Prescott SA, De Koninck Y (2005) Integration time in a subset of spinal lamina I neurons is lengthened by sodium and calcium currents acting synergistically to prolong subthreshold depolarization. J Neurosci 25:4743-4754.

Ramirez JM, Tryba AK, Peña F (2004) Pacemaker neurons and neuronal networks: an integrative view. Curr Opin Neurobiol 14:665-674.

Ruscheweyh R, Ikeda H, Heinke B, Sandkühler J (2004) Distinctive membrane and discharge properties of rat spinal lamina I projection neurones in vitro. J Physiol 555:527-543.

Russo RE, Hounsgaard J (1996) Burst-generating neurones in the dorsal horn in an in vitro preparation of the turtle spinal cord. J Physiol 493:55-66.

Ryu PD, Randic M (1990) Low- and high-voltage-activated calcium currents in rat spinal dorsal horn neurons. J Neurophysiol 63:273-285.
Sah P (1996) $\mathrm{Ca}^{2+}$-activated $\mathrm{K}^{+}$currents in neurones: types, physiological roles and modulation. Trends Neurosci 19:150-154

Schouenborg J (2008) Action-based sensory encoding in spinal sensorimotor circuits. Brain Res Rev 57:111-117.

Schwindt PC, Spain WJ, Crill WE (1992) Effects of intracellular calcium chelation on voltage-dependent and calcium-dependent currents in cat neocortical neurons. Neuroscience 47:571-578.

Shatz CJ, Stryker MP (1988) Prenatal tetrodotoxin infusion blocks segregation of retinogeniculate afferents. Science 242:87-89.

Sheroziya MG, von Bohlen Und Halbach O, Unsicker K, Egorov AV (2009) Spontaneous bursting activity in the developing entorhinal cortex. J Neurosci 29:12131-12144.

Shiokawa H, Kaftan EJ, MacDermott AB, Tong CK (2010) NR2 subunits and NMDA receptors on lamina II inhibitory and excitatory interneurons of the mouse dorsal horn. Mol Pain 6:26.

Spike RC, Puskár Z, Andrew D, Todd AJ (2003) A quantitative and morphological study of projection neurons in lamina I of the rat lumbar spinal cord. Eur J Neurosci 18:2433-2448.

Stellwagen D, Shatz CJ (2002) An instructive role for retinal waves in the development of retinogeniculate connectivity. Neuron 33:357-367.

Szucs P, Luz LL, Lima D, Safronov BV (2010) Local axon collaterals of lamina I projection neurons in the spinal cord of young rats. J Comp Neurol 518:2645-2665.

Thoby-Brisson M, Karlén M, Wu N, Charnay P, Champagnat J, Fortin G (2009) Genetic identification of an embryonic parafacial oscillator coupling to the preBötzinger complex. Nat Neurosci 12:1028-1035.

Todd AJ, Sullivan AC (1990) Light microscope study of the coexistence of GABA-like and glycine-like immunoreactivities in the spinal cord of the rat. J Comp Neurol 296:496-505.

Tritsch NX, Yi E, Gale JE, Glowatzki E, Bergles DE (2007) The origin of spontaneous activity in the developing auditory system. Nature 450:50-55.

Urbani A, Belluzzi O (2000) Riluzole inhibits the persistent sodium current in mammalian CNS neurons. Eur J Neurosci 12:3567-3574.

Waldenström A, Thelin J, Thimansson E, Levinsson A, Schouenborg J (2003) Developmental learning in a pain-related system: evidence for a cross-modality mechanism. J Neurosci 23:7719-7725.

Wiesel TN, Hubel DH (1963) Single-cell responses in striate cortex of kittens deprived of vision in one eye. J Neurophysiol 26:1003-1017.

Yasaka T, Tiong SY, Hughes DI, Riddell JS, Todd AJ (2010) Populations of inhibitory and excitatory interneurons in lamina II of the adult rat spinal dorsal horn revealed by a combined electrophysiological and anatomical approach. Pain 151:475-488.

Zheng J, Lee S, Zhou ZJ (2006) A transient network of intrinsically bursting starburst cells underlies the generation of retinal waves. Nat Neurosci 9:363-371. 